\title{
A three-dimensional approach for contact detection between realistic wheel and rail surfaces for improved railway dynamic analysis
}

\author{
Filipe Marques $^{1 *}$, Hugo Magalhães ${ }^{2,3}$, João Pombo ${ }^{2,3,4}$, Jorge Ambrósio ${ }^{3}$ and Paulo Flores ${ }^{1}$ \\ ${ }^{1}$ CMEMS-UMinho, Departamento de Engenharia Mecânica, Universidade do Minho, \\ Campus de Azurém, 4804-533 Guimarães, Portugal \\ ${ }^{2}$ Institute of Railway Research, University of Huddersfield, Huddersfield, UK \\ ${ }^{3}$ IDMEC, Instituto Superior Técnico, Universidade de Lisboa, \\ Avenida Rovisco Pais 1, 1049-001 Lisboa, Portugal \\ ${ }^{4}$ ISEL, IPL, Lisboa, Portugal
}

\begin{abstract}
The wheel-rail contact modelling problem assumes a preponderant role on the dynamic analysis of railway systems using multibody systems formulations. The accurate and efficient evaluation of both location and magnitude of the wheel-rail contact forces is fundamental for the development of reliable computational tools. The wheel concave zone might be a source of numerical difficulties when searching the contact points, which has been neglected in several works. Here, it is demonstrated that the minimum distance method does not always converge when the wheel surface is not fully convex, being an alternative methodology proposed to perform the contact detection. This approach examines independently the contact between each wheel strip and the rail, where the maximum virtual penetration is determined and associated with the location of the contact point. Then, an Hertzian-based force model is considered for both normal and tangential forces. The results obtained from dynamic simulations show that the minimum distance method and the proposed methodology provide a similar response for simplified wheel profiles. However, the new approach described here is reliable in the identification of the contact point when realistic wheel profiles are considered, which is not the case with the minimum distance method.
\end{abstract}

Keywords: Wheel-Rail Contact, Contact Detection, Conformal Contact, Railway Dynamics

\section{Introduction}

The study of railway vehicle dynamics by using multibody systems methodologies has been increasing its popularity in the past years, due to its efficiency and reliability to formulate and solve different type of problems [1-4], namely virtual homologation of vehicles [5,6], study of the vehicle performance for selected tracks [7,8], derailments prevention [9-12], design of suspension, traction or braking systems [13-15], just to mention a few. One of the major issues concerning the dynamic modelling and simulation of railway vehicles deals with the evaluation of the vehicle-track interaction, which consists of the solution of the contact between the wheels and the rails. This issue plays a key role on the multibody simulations since it not only affects the motion of the vehicle [16] but also allows the study and prediction of some damaging phenomena, such as wear [17-21] or rolling contact fatigue $[22,23]$. In fact, the development of accurate and efficient methodologies to deal with the assessment of wheel-rail contact became an important research topic for railway system dynamics $[24,25]$.

The solution of a general contact problem between two or more bodies is a quite frequent issue in the context of a multibody system dynamics [26-31]. The contact is a complex phenomenon

\footnotetext{
* Corresponding author, Tel: + 351 253510220, Fax: +351 253516007, E-mail: fmarques@ dem.uminho.pt
} 
which involves high force levels, energy dissipation and rapid changes in the velocity of the bodies. Several works demonstrate that the use of different contact modeling methodologies has a significant influence on the dynamic response of the system [32-34]. Hence, the accurate and detailed modelling of contact events is of paramount importance. During the solution of the contact problems, two distinct phases must be taken into consideration. First, the detection of contact location between the potentially colliding bodies needs to be efficiently performed, afterwards, the contact forces must be accurately evaluated. When the colliding bodies present simple geometries, the contact detection phase can be a straightforward task and solved analytically. However, in the most general case, where the contacting surfaces have an arbitrary shape, the search for potential contact points might become a demanding and complex task $[3,35]$.

The contact detection methodologies to handle the wheel-rail contact can be categorized into two main groups, namely the constraint approach and the elastic formulation. The constraint approach involves the definition of nonlinear kinematic contact constraints between the wheel and rail, being the contact point determined during the resolution of the equations of motion [36-40]. This approach considers the contact fully rigid and reduces to five the number of degrees-of-freedom of the wheel relatively to the rail. In turn, the elastic formulation allows the penetration between the wheel and rail profiles assuming that the bodies can be locally deformable $[27,35,41,42]$. Thus, the contact forces are evaluated as external forces and the wheel keeps its six degrees-of-freedom with respect to the rail. In the context of this work, the elastic formulation is used to formulate the contact problem as it allows the evaluation of wheel-rail contact in an effective manner [38].

Regardless of the procedure used to handle the contact detection and evaluate the contact forces, it is of paramount importance to correctly describe the geometry of the interacting surfaces. Although the real wheel and rail profiles exhibit a complex shape, simple profiles have been used with the purpose of developing analytical solutions of the vehicle and track dynamics at a time in which access to computational calculation was very limited [43-45]. More detailed numerical procedures are required in order to accurately model the actual wheel and rail geometries, that is, to consider the different wheel and rail geometric regions which are mathematically described in the standards for new profiles [46,47]. Among the existing approaches, one of the most popular consists of describing the wheel and rail profiles by the polynomial interpolation of a given set of points, namely by polynomial splines $[17,41,48]$. This procedure proves to be valuable in view of the advantage of exhibiting local geometrical control, i.e., the variation of the position of a particular control point only affects its neighborhood without changing the rest of the curve [49]. Subsequently to the description of profiles, which are fundamentally two-dimensional curves, it is necessary to extend their representation to the three-dimensional space and fully define the contacting surfaces. Typically, the wheel and rail can be represented by parametric surfaces [37,50-52]. The rail surface is obtained through the sweep of its cross-section along a given path, while the wheel surface is described as a revolution of its cross-section about an axis. At this stage, it must be highlighted that the presence of track irregularities or surface defects might affect the definition of the contacting geometries [53,54]. However, these irregularities have specific treatments, from the numerical point of view, which do not affect the general approach described here.

Regarding the wheel-rail interaction scenarios, most of the cases involve a non-conformal configuration of the surfaces in the neighbourhood of the contact zone. This is, when the rail interacts separately with both wheel flange and wheel tread, the contacting surfaces present a convex shape. However, for worn wheel profiles and some wheel-rail configurations, the contact can occur on the running fillet and, hence, the contact becomes conformal. In order to expedite the contact detection procedure, several works neglect the transition zone between the tread and the flange, which is concave, and represent the wheel profile as the aggregation of two independent convex curves $[41,52,55]$. This simplification is computationally efficient and avoids numerical difficulties $[39,56]$, however, it does not permit to study in detail the local phenomena associated with wheelrail interaction, such as for wear or rolling contact fatigue studies. Furthermore, the investigation of the contact in concave zones allows the detailed study of conformal contact which had received little attention when compared with the non-conformal one. In this type of contact, the assumption of a 
planar contact region is not valid, therefore, the patch curvature must be considered [57], having a significant effect on surface tractions, subsurface stresses and frictional work distributions $[58,59]$.

The strategy utilized to perform the search of contact points is closely related to the geometric description of the potential contacting surfaces. Thus, algebraic approaches can be employed $[2,60]$ in which the contact points are sought in a continuous manner through constraints imposed to the normal and tangential vectors. On the other hand, the nodal search method performs a discrete evaluation of the penetration between profiles for each node $[61,62]$, which typically has higher computational cost. Moreover, the contact detection procedure strongly affects the efficiency and accuracy of the overall contact modelling. In a broad sense, the contact search can be performed in one of two ways, namely online or offline. In the former, the location of the contact points is determined online using iterative procedures at every time step of the dynamic simulation [35,41]. In the offline approach, the location of the contact points is precomputed by the contact geometry analysis, and this information is stored in a lookup table which is invoked in each time step of the integration [38,63-66].

The main goal of the present work is to address the issues associated with the utilization of wheel profiles with geometry simplifications to improve efficiency of railway dynamic simulations. As discussed above, it is a common procedure to neglect the transition zone between wheel tread and wheel flange in order to avoid a concave area on the wheel surface. The approach here is to consider such transition zone, a concave region, and develop a new approach for contact detection between realistic wheel and rail surfaces. The benefits of the approach are demonstrated by developing a running scenario in which the dynamic response of a railway vehicle with real profiles is compared with the case where only convex profiles are considered.

The remainder of this paper is organized as follows. Section 2 provides the parametrization of both wheel and rail surfaces, which demonstrates the calculation of surface points, normal and tangential vectors, and surface curvatures based on their parameters. The explanation of the minimum distance method, as well of a novel methodology to deal with the contact search in the case of existence of concave wheel surface, are described in Section 3. Then, the normal and tangential contact force models utilized in this work are described in Section 4. In Section 5, the multibody dynamics formulation employed here is revisited. Section 6 provides three different examples of application to show the effectiveness and reliability of the proposed contact detection methodology. Finally, the main conclusions are drawn in Section 7.

\section{Wheel and rail geometric definition}

\subsection{Wheel and rail geometric parametrization}

Since the geometry of the contacting surfaces constrains the possible contact scenarios, it is crucial to have an accurate and complete description of the wheel and rail geometries. Hence, in this work, wheels and rails are mathematically represented by parametrized surfaces, i.e., the location of any point on each of the surfaces can be defined by two parameters $[3,41]$. Thus, the surface of each rail is obtained through the sweep of its cross-section along a given path, which is represented by a set of nodal points and interpolated with a suitable spline. These nodal points define the position and orientation of the rail as function its arclength, $s_{\mathrm{r}}^{\text {side }}$. Note that the superscript side can be defined as "L" or "R", whether it refers to the left or right rails, respectively. The position of the origin of the rail profile is defined by $\mathbf{r}_{\mathrm{r}}^{\text {side }}$ vector, and its orientation is given by a set of vectors $\mathbf{t}_{\mathrm{r}}^{\text {side }}, \mathbf{n}_{\mathrm{r}}^{\text {side }}$ and $\mathbf{b}_{\mathrm{r}}^{\text {side }}$, which represent the tangent, normal and binormal vectors, respectively. These vectors are depicted in Fig. 1. For each rail, the value of these four vectors, in all nodal points, are stored in a database, which is obtained with the pre-processor tool that uses the nominal track design geometry, namely, its curvature and cant angle, and the track irregularities to generate the current track geometry used in the railway dynamic analyses [53,67]. In order to obtain the rail data for a given location, i.e. $s_{\mathrm{r}}^{\text {side }}$, the nodal points data is interpolated using cubic polynomials, which guarantees second order continuity. Then, the rail profile is represented by a two-dimensional function, in which $u_{\mathrm{r}}^{\text {side }}$ is the surface parameter that defines the lateral rail 
coordinate and $f_{\mathrm{r}}^{\text {side }}$ denotes the dependent vertical coordinate, as it is displayed in Fig. 2(a). It must be noted that the directions of $u_{\mathrm{r}}^{\text {side }}$ and $f_{\mathrm{r}}^{\text {side }}$ coincide with the normal and binormal vectors of the rail, as represented in Fig. 1. In turn, since the wheelset is a body of revolution, the wheel surface can be defined by the rotation of its cross-section about its own axis. Thus, any point in the wheel surface is characterized by the angular position $s_{\mathrm{w}}^{\text {side }}$, and the lateral coordinate $u_{\mathrm{w}}^{\text {side }}$. In a similar manner, the wheel profile is represented by a two-dimensional function, in which $f_{\mathrm{w}}^{\text {side }}$ denotes the dependent wheel profile coordinate, as depicted in Fig. 2(b).

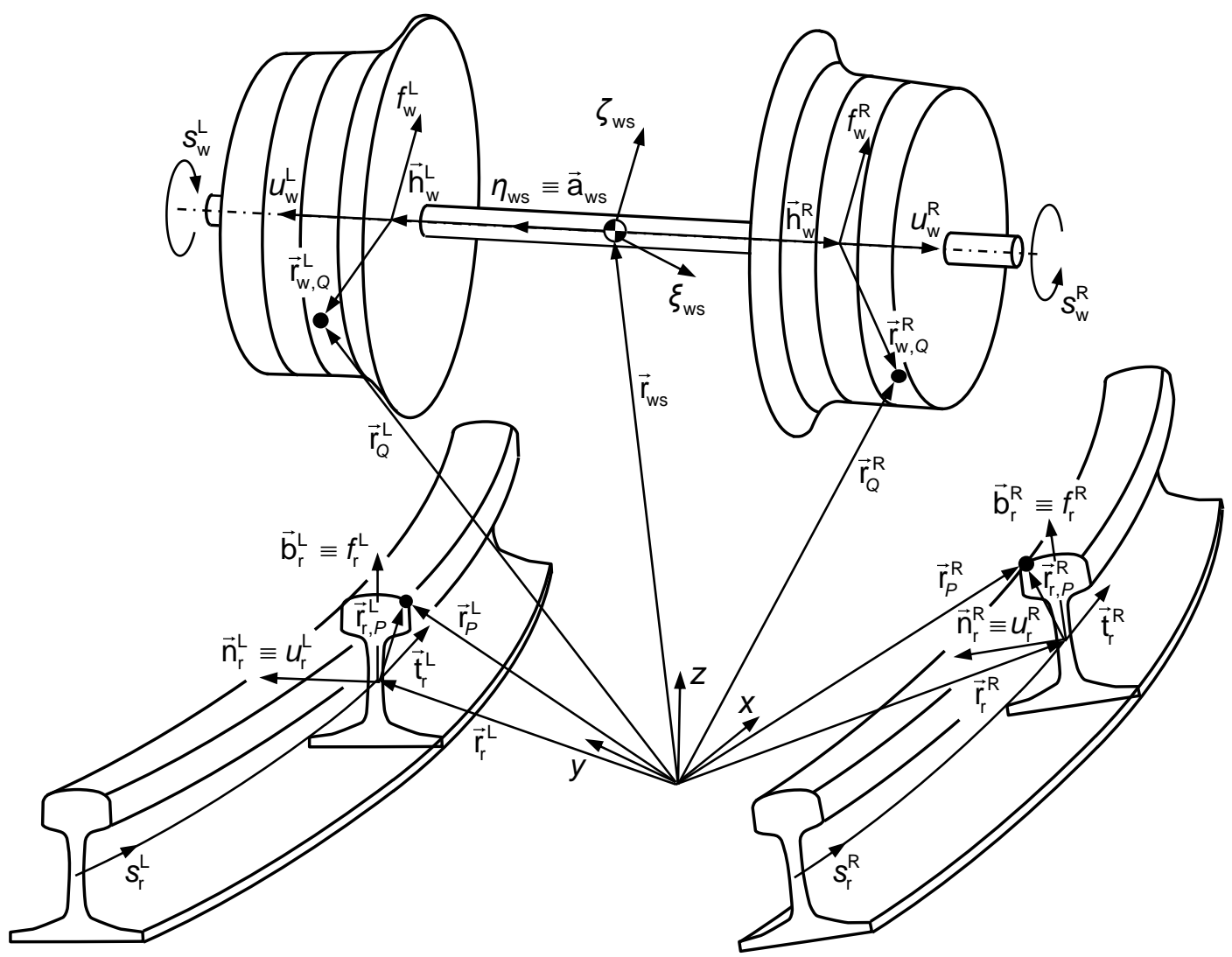

Fig. 1 Parametrization of wheel and rail surfaces.

The definition of both wheel and rail cross sections represented in Fig. 2 can be performed through an analytical function or with a set of nodal points, in which the continuous evaluation of both profiles is commonly performed by using a cubic spline interpolation of these nodal points. In the present work, the wheel and rail profiles are defined analytically according the respective standards $[46,47]$.

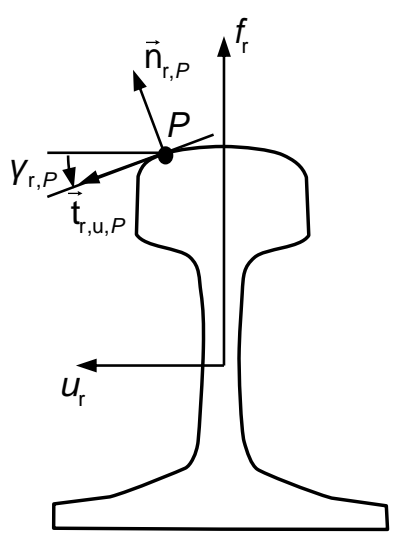

(a)

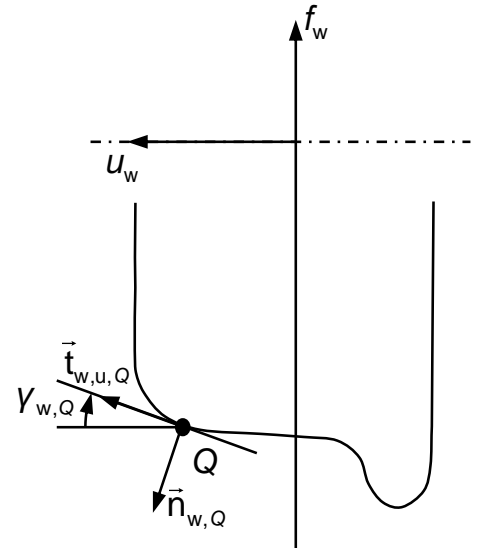

(b)

Fig. 2 Representation of an arbitrary point and normal and tangential vectors on (a) rail and (b) wheel profiles in their local coordinate system. 
Based on the surface parametrizations described, and pictured in Fig. 1. Two arbitrary points, $P$ and $Q$, that can be defined in the rail and wheel surfaces, respectively, as function of the surface parameters: $s_{\mathrm{r}, P}^{\text {side }}, u_{\mathrm{r}, P}^{\text {side }}, s_{\mathrm{w}, Q}^{\text {side }}$ and $u_{\mathrm{w}, Q}^{\text {side }}$. The position of point $P$ is expressed as

$$
\mathbf{r}_{P}^{\text {side }}=\mathbf{r}_{\mathrm{r}}^{\text {side }}+\mathbf{r}_{\mathrm{r}, P}^{\text {side }}
$$

where $\mathbf{r}_{\mathrm{r}}^{\text {side }}$ denotes the position vector of the origin of the rail profile, which is a function of the rail arclength $s_{\mathrm{r}, P}^{\text {side }}$, and $\mathbf{r}_{\mathrm{r}, P}^{\text {side }}$ represents the distance vector between the rail profile origin and point $P$ that is calculated as

$$
\mathbf{r}_{\mathrm{r}, P}^{\text {side }}=\mathbf{A}_{\mathrm{r}}^{\text {side }} \mathbf{r}_{\mathrm{r}, P, \mathrm{r}}^{\text {side }}
$$

in which $\mathbf{r}_{\mathrm{r}, P, \mathrm{r}}^{\text {side }}$ denotes the vector $\mathbf{r}_{\mathrm{r}, P}^{\text {side }}$ in the rail local coordinate system, and $\mathbf{A}_{\mathrm{r}}^{\text {side }}$ is the rail transformation matrix associated with its local coordinate system. Both $\mathbf{r}_{\mathrm{r}, P, \mathrm{r}}^{\text {side }}$ and $\mathbf{A}_{\mathrm{r}}^{\text {side }}$ can be defined by

$$
\begin{aligned}
\mathbf{r}_{\mathrm{r}, P, \mathrm{r}}^{\text {side }} & =\left[\begin{array}{lll}
0 & u_{\mathrm{r}, P}^{\text {side }} & f_{\mathrm{r}, P}^{\text {side }}
\end{array}\right]^{\mathrm{T}} \\
\mathbf{A}_{\mathrm{r}}^{\text {side }} & =\left[\begin{array}{lll}
\mathbf{t}_{\mathrm{r}}^{\text {side }} & \mathbf{n}_{\mathrm{r}}^{\text {side }} & \mathbf{b}_{\mathrm{r}}^{\text {side }}
\end{array}\right]
\end{aligned}
$$

where $u_{\mathrm{r}, P}^{\text {side }}$ is the lateral rail surface parameter of point $P, f_{\mathrm{r}, P}^{\text {side }}$ denotes the ordinate of the rail profile function for the position $u_{\mathrm{r}, P}^{\text {side }}$ as shown in Fig. 2(a), and $\mathbf{t}_{\mathrm{r}}^{\text {side }}, \mathbf{n}_{\mathrm{r}}^{\text {side }}$ and $\mathbf{b}_{\mathrm{r}}^{\text {side }}$ are, respectively, the tangent, normal and binormal vectors of the rail for a given $s_{\mathrm{r}, P}^{\text {side }}$ as depicted in Fig. 1.

An arbitrary point $Q$ located on the wheel surface, following the representation provided in Fig. 1, can be calculated as

$$
\mathbf{r}_{Q}^{\text {side }}=\mathbf{r}_{\mathrm{ws}}+\mathbf{h}_{\mathrm{w}}^{\text {side }}+\mathbf{r}_{\mathrm{w}, Q}^{\text {side }}
$$

in which $\mathbf{r}_{\mathrm{ws}}$ is the position vector of wheelset center of mass, $\mathbf{h}_{\mathrm{w}}^{\text {side }}$ represents the relative position between the wheelset center of mass and the origin of the wheel local coordinate system, which is defined differently according whether it refers to the left or right side, i.e.,

$$
\mathbf{h}_{\mathrm{w}}^{\mathrm{L}}=\mathbf{A}_{\mathrm{ws}}\left[\begin{array}{lll}
0 & H / 2 & 0
\end{array}\right]^{\mathrm{T}} \quad \text { or } \quad \mathbf{h}_{\mathrm{w}}^{\mathrm{R}}=\mathbf{A}_{\mathrm{ws}}\left[\begin{array}{lll}
0 & -H / 2 & 0
\end{array}\right]^{\mathrm{T}}
$$

where $H$ denotes the distance between left and right wheel profiles and $\mathbf{A}_{\mathrm{ws}}$ is the wheelset transformation matrix which defines the orientation of the wheelset local coordinate system relatively to the global coordinate system [68]. The vector $\mathbf{r}_{\mathrm{w}, Q}^{\text {side }}$ represents the distance between the wheel profile origin and point $Q$, which is defined as

$$
\mathbf{r}_{\mathrm{w}, Q}^{\text {side }}=\mathbf{A}_{\mathrm{ws}} \mathbf{A}_{\mathrm{w}, \mathrm{S}}^{\text {side }} \mathbf{r}_{\mathrm{w}, Q, \mathrm{w}}^{\text {side }}
$$

where $\mathbf{r}_{\mathrm{w}, Q, \mathrm{w}}^{\text {side }}$ is the vector $\mathbf{r}_{\mathrm{w}, Q}^{\text {side }}$ in the wheel local coordinate system and it is given as

$$
\mathbf{r}_{\mathrm{w}, Q, \mathrm{w}}^{\text {side }}=\left[\begin{array}{lll}
0 & u_{\mathrm{w}, Q}^{\text {side }} & f_{\mathrm{w}, Q}^{\text {side }}
\end{array}\right]^{\mathrm{T}}
$$

in which, similarly to the rail case, $u_{\mathrm{w}, Q}^{\text {side }}$ is the lateral wheel surface parameter of point $Q$ and $f_{\mathrm{w}, Q}^{\text {side }}$ denotes the ordinate of the wheel profile function for the position $u_{\mathrm{w}, Q}^{\text {side }}$. The transformation matrix $\mathbf{A}_{\mathrm{w}, \mathrm{s}}^{\text {side }}$ specifies the rotation around the wheel axis, is dependent on the angular wheel surface parameter of point $Q, s_{\mathrm{w}, Q}^{\text {side }}$, and is defined as

$$
\mathbf{A}_{\mathrm{w}, \mathrm{s}}^{\mathrm{L}}=\left[\begin{array}{ccc}
\cos \left(s_{\mathrm{w}, Q}^{\mathrm{L}}\right) & 0 & \sin \left(s_{\mathrm{w}, Q}^{\mathrm{L}}\right) \\
0 & 1 & 0 \\
-\sin \left(s_{\mathrm{w}, Q}^{\mathrm{L}}\right) & 0 & \cos \left(s_{\mathrm{w}, Q}^{\mathrm{L}}\right)
\end{array}\right] \quad \text { or } \quad \mathbf{A}_{\mathrm{w}, \mathrm{s}}^{\mathrm{R}}=\left[\begin{array}{ccc}
-\cos \left(s_{\mathrm{w}, Q}^{\mathrm{R}}\right) & 0 & -\sin \left(s_{\mathrm{w}, Q}^{\mathrm{R}}\right) \\
0 & -1 & 0 \\
-\sin \left(s_{\mathrm{w}, Q}^{\mathrm{R}}\right) & 0 & \cos \left(s_{\mathrm{w}, Q}^{\mathrm{R}}\right)
\end{array}\right]
$$


The definition of both normal and tangential vectors of the parametrized surfaces on the arbitrary points, $P$ and $Q$, is required to perform the contact detection, whereas the local curvatures at the contact points are used to solve the normal contact force problem. Regarding the rail surface, the tangential vectors on the longitudinal and lateral directions on point $P$ are expressed, respectively, as

$$
\begin{gathered}
\mathbf{t}_{\mathrm{r}, \mathrm{s}, P}^{\text {side }}=\mathbf{t}_{\mathrm{r}}^{\text {side }} \\
\mathbf{t}_{\mathrm{r}, \mathrm{u}, P}^{\text {side }}=\mathbf{A}_{\mathrm{r}}^{\text {side }} \mathbf{t}_{\mathrm{r}, \mathrm{u}, P, \mathrm{r}}^{\text {side }}
\end{gathered}
$$

in which the tangential vector of the rail in the lateral direction on point $P$ in the rail local coordinate system is given by

$$
\mathbf{t}_{\mathrm{r}, \mathrm{u}, P, \mathrm{r}}^{\text {side }}=\left[\begin{array}{lll}
0 & \cos \left(\gamma_{\mathrm{r}, P}^{\text {side }}\right) & \sin \left(\gamma_{\mathrm{r}, P}^{\text {side }}\right)
\end{array}\right]^{\mathrm{T}}
$$

where $\gamma_{\mathrm{r}, P}^{\text {side }}$ is rail contact angle, which is defined by the angle between the tangent to the rail profile and the lateral direction, as shown in Fig. 2(a). Thus, the contact angle is

$$
\gamma_{\mathrm{r}, P}^{\text {side }}=\arctan \left(f_{\mathrm{r}, P}^{\prime \text { side }}\right)
$$

The following notation is employed to denote the profile derivatives

$$
f_{k, P}^{\text {side }}=\frac{\mathrm{d} f_{k}^{\text {side }}\left(u_{k, P}^{\text {side }}\right)}{\mathrm{d} u_{k}^{\text {side }}} \quad \text { and } \quad f_{k, P}^{\text {"side }}=\frac{\mathrm{d}^{2} f_{k}^{\text {side }}\left(u_{k, P}^{\text {side }}\right)}{\mathrm{d} u_{k}^{\text {side } 2}}, \quad k=\mathrm{w}, \mathrm{r}
$$

In a similar manner, the normal vector to the rail profile is calculated as

$$
\mathbf{n}_{\mathrm{r}, P}^{\text {side }}=\mathbf{A}_{\mathrm{r}}^{\text {side }} \mathbf{n}_{\mathrm{r}, P, \mathrm{r}}^{\text {side }}
$$

where

$$
\mathbf{n}_{\mathrm{r}, P, \mathrm{r}}^{\text {side }}=\left[\begin{array}{lll}
0 & -\sin \left(\gamma_{\mathrm{r}, P}^{\text {side }}\right) & \cos \left(\gamma_{\mathrm{r}, P}^{\text {side }}\right)
\end{array}\right]^{\mathrm{T}}
$$

Furthermore, the local lateral and longitudinal curvatures of rail surface are computed, respectively, as

$$
\begin{gathered}
\kappa_{\mathrm{r}, P}^{\mathrm{u} \text {,side }}=\frac{1}{R_{\mathrm{r}, P}^{\mathrm{u}, \text { side }}}=-\frac{f_{\mathrm{r}, P}^{\text {"side }}}{\left(1+\left(f_{\mathrm{r}, P}^{\prime \text { side }}\right)^{2}\right)^{3 / 2}} \\
\kappa_{\mathrm{r}, P}^{\mathrm{s} \text {,side }}=0
\end{gathered}
$$

It must be noticed that the longitudinal rail curvature is considered to be null since the slope variations can be negligible for actual tracks.

In what concerns the wheel surface, the tangent vector in the longitudinal direction on point $Q$ is

$$
\mathbf{t}_{\mathrm{w}, \mathrm{s}, Q}^{\text {side }}=\mathbf{A}_{\mathrm{ws}} \mathbf{A}_{\mathrm{w}, \mathrm{s}}^{\text {side }} \mathbf{t}_{\mathrm{w}, \mathrm{s}, Q, \mathrm{w}}^{\text {side }}
$$

in which the tangent vector in the local coordinate system of the wheel is expressed differently for the left and right sides as

$$
\mathbf{t}_{\mathrm{w}, \mathrm{s}, Q, \mathrm{w}}^{\mathrm{L}}=\left[\begin{array}{lll}
1 & 0 & 0
\end{array}\right]^{\mathrm{T}} \quad \text { or } \quad \mathbf{t}_{\mathrm{w}, \mathrm{s}, Q, \mathrm{w}}^{\mathrm{R}}=\left[\begin{array}{lll}
-1 & 0 & 0
\end{array}\right]^{\mathrm{T}}
$$

while the tangent of the wheel surface in lateral direction is

$$
\mathbf{t}_{\mathrm{w}, \mathrm{u}, Q}^{\text {side }}=\mathbf{A}_{\mathrm{ws}} \mathbf{A}_{\mathrm{w}, \mathrm{s}}^{\text {side }} \mathbf{t}_{\mathrm{w}, \mathrm{u}, Q, \mathrm{w}}^{\text {side }}
$$


in which

$$
\mathbf{t}_{\mathrm{w}, \mathrm{u}, Q, \mathrm{w}}^{\text {side }}=\left[\begin{array}{lll}
0 & \cos \left(\gamma_{\mathrm{w}, Q}^{\text {side }}\right) & \sin \left(\gamma_{\mathrm{w}, Q}^{\text {side }}\right)
\end{array}\right]^{\mathrm{T}}
$$

where $\gamma_{\mathrm{w}, Q}^{\text {side }}$ denotes the wheel contact angle on point $Q$, which is represented in Fig. 2(b) and given by

$$
\gamma_{\mathrm{w}, Q}^{\text {side }}=\arctan \left(f_{\mathrm{w}, Q}^{\text {side }}\right)
$$

The normal surface vector is

$$
\mathbf{n}_{\mathrm{w}, Q}^{\text {side }}=\mathbf{A}_{\mathrm{ws}} \mathbf{A}_{\mathrm{w}, \mathrm{s}}^{\text {side }} \mathbf{n}_{\mathrm{w}, Q, \mathrm{w}}^{\text {side }}
$$

in which

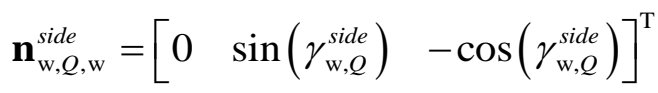

Finally, the local curvature of the wheel surface in the lateral direction is computed, in an analogous manner to the rail surface, as

$$
\kappa_{\mathrm{w}, Q}^{\mathrm{u}, \text { side }}=\frac{1}{R_{\mathrm{w}, Q}^{\mathrm{u}, \text { side }}}=\frac{f_{\mathrm{w}, Q}^{\text {"side }}}{\left.\left(1+\left(f_{\mathrm{w}, Q}^{\prime},\right)^{\text {side }}\right)^{2}\right)^{3 / 2}}
$$

while the local curvature of longitudinal direction is given by

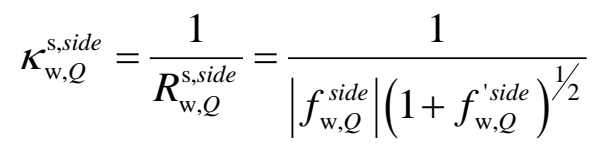

\subsection{Wheel profile definition}

The mathematical representation of wheel and rail profiles plays an important role on the study of the wheel-rail contact interaction, since it significantly affects the location of contact points, as well as the magnitude and orientation of the contact forces. Whether the wheel and rail profiles are defined analytically or by a set of interpolated points, which is more appropriate when representing worn surfaces, the transition zone between the tread and the flange is often neglected. In this case, the profile is simplified, and the concave region of the wheel is disregarded to avoid performing the contact detection in the negative curvature zone $[41,52,55]$.

For a new wheel, the analytical definition of the profile is typically given in the respective standard as a piecewise function [46]. Figure 3(a) depicts the S1002 wheel profile for a nominal radius equal to $0.43 \mathrm{~m}$, which is utilized in this work. It must be highlighted that, in contrast to the first derivative of the wheel profile, shown in Fig. 3(c), its second derivative is not a continuous function, as observed in Fig. 3(e). Based on the computed derivatives and recurring to Eq. (26), the profile curvature is displayed in Fig. 3(g), which consequently exhibits discontinuities. Hence, the curvature of the profile is negative where its lateral coordinate assumes values between -38.4 $\mathrm{mm}$ and $14.0 \mathrm{~mm}$, approximately. Thus, to simplify the wheel profile in order to obtain a nonconformal or fully convex wheel surface, the profile curvature is specified to be zero in this region, which means that two straight lines are drawn from the boundary points keeping the same slope until they intersect each other. The simplified wheel is profile plotted in Fig. 3(b). Therefore, this profile can easily be divided into two separate convex curves, one for the tread and another for the flange, each one used independently in the contact detection between wheel and rail. The boundary between these two regions may results in a singular point, however, it must be noted that it is not physically possible that the contact occurs in such a point. 


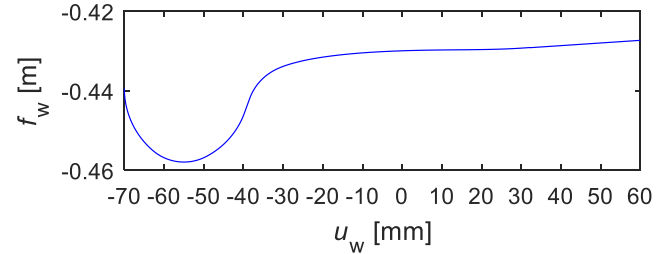

(a)

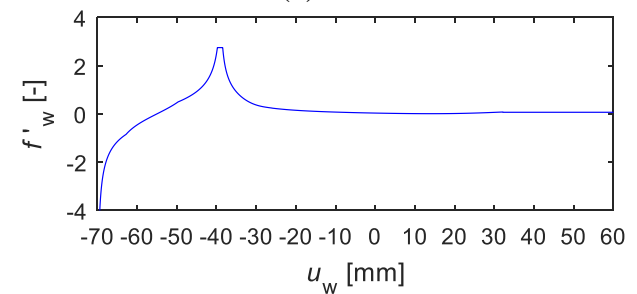

(c)

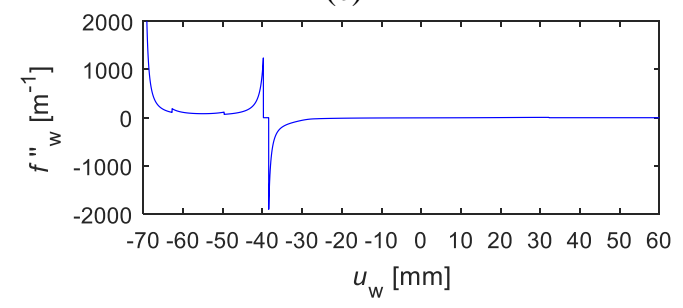

(e)

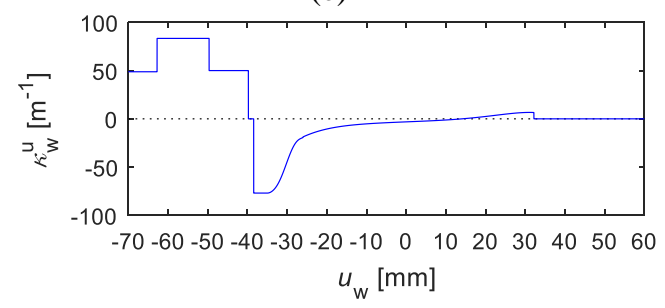

(g)

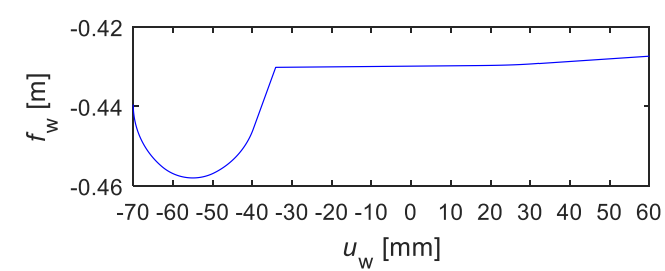

(b)

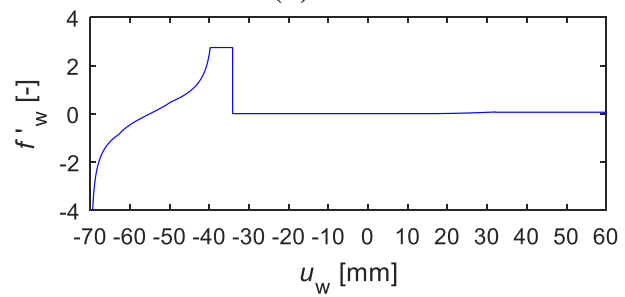

(d)

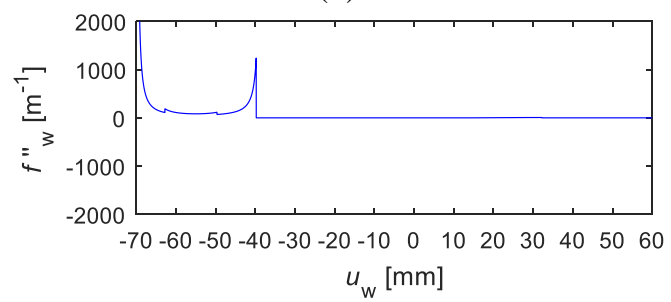

(f)

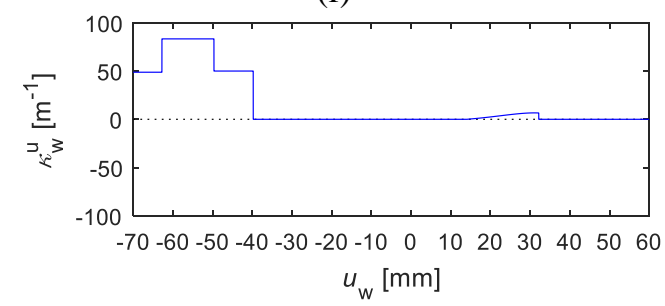

(h)

Fig. 3 Representation of an original S1002 profile and a modified non-conformal profile, respectively,

(a)-(b) the profile function, (c)-(d) first derivative, (e)-(f) second derivative, and (g)-(h) curvature

Since the new rail profile is always convex [47] when using Eqs. (18) and (27) to evaluate the curvature of the surfaces in the rolling direction, it can be noticed that the modified wheel profile ensures that the resulting contacting surfaces are non-conformal. This property may have a paramount importance on the convergence of the contact detection methodologies; however, their utilization does not allow the detailed study of local wheel-rail interaction issues, as wear or rolling contact fatigue, and it is relevant to verify the actual influence of these approximated profiles on the dynamic response of railway systems.

\section{Contact detection methodology}

The contact detection procedure plays a key role on the efficiency and accuracy of the dynamic analysis of multibody systems with contact interactions. Its relevance increases with the increasing complexity of the contacting surfaces, such as in the case of wheel-rail interaction. In this section, two different contact detection methodologies are discussed. First, the minimum distance method is described, which has been widely utilized for searching the potential contact points between convex surfaces $[3,41,69,70]$. Subsequently, an alternative approach for the wheelrail contact is introduced which can be applied to real wheel profiles that comprise non-convex regions.

\subsection{Minimum Distance Method}

Regarding the utilization of elastic contact force models for the wheel-rail interaction, as considered in this work, the main contact points typically exhibit the maximum virtual penetration between potential contact surfaces. For the case of two arbitrary convex surfaces, as represented in Fig. 4, the contact points can be found through the minimum distance condition, that is, when the 
distance vector between the two points and their normal vectors to the surface are collinear. Since the mathematical definition of two collinear or parallel vector is given by their null cross product, three mathematical expression can be obtained

$$
\begin{aligned}
& \mathbf{d}^{\text {side }} \times \mathbf{n}_{\mathrm{w}, Q}^{\text {side }}=\mathbf{0} \\
& \mathbf{d}^{\text {side }} \times \mathbf{n}_{\mathrm{r}, P}^{\text {side }}=\mathbf{0} \\
& \mathbf{n}_{\mathrm{r}, P}^{\text {side }} \times \mathbf{n}_{\mathrm{w}, Q}^{\text {side }}=\mathbf{0}
\end{aligned}
$$

in which the distance vector is defined as

$$
\mathbf{d}^{\text {side }}=\mathbf{r}_{Q}^{\text {side }}-\mathbf{r}_{P}^{\text {side }}
$$

and the normal vectors are evaluated as described in the previous section.

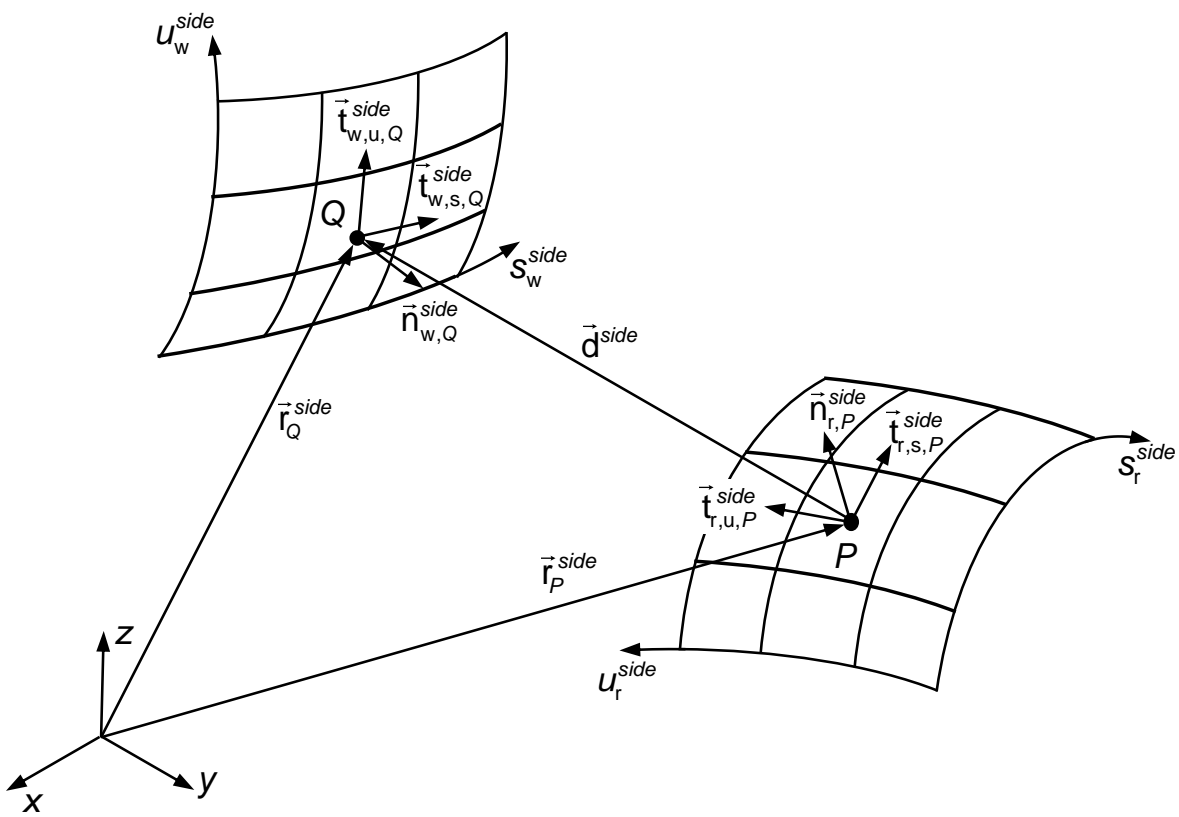

Fig. 4 Schematic representation of wheel and rail parametric surfaces for contact detection purposes.

The three constraints of Eq. (28) consists of a redundant set of equations, since two of them are enough to ensure the parallelism between the distance vector, $\mathbf{d}^{\text {side }}$, the normal vector to the wheel, $\mathbf{n}_{\mathrm{w}, Q}^{\text {side }}$, and the normal vector to the rail, $\mathbf{n}_{\mathrm{r}, P}^{\text {side }}$. If the first two conditions are selected, the constraint equations are satisfied, not only when the distance vector is parallel to the normal vectors, but also when the distance vector is null, which is an inappropriate contact detection case. Therefore, one of the first two conditions given in Eq. (28) must be disregarded. Bearing this in mind, and using the equivalence between the cross product of a given vector and a normal vector to the surface and the inner products of this vector and the tangent vectors to that surface, the minimum distance condition establishes a system of four nonlinear equations, which can assume two different forms, that is, $[3,41]$

$$
\begin{aligned}
& \mathbf{F}_{\mathrm{nl}}\left(s_{\mathrm{r}, P}^{\text {side }}, u_{\mathrm{r}, P}^{\text {side }}, s_{\mathrm{w}, Q}^{\text {side }}, u_{\mathrm{w}, Q}^{\text {side }}\right)=\mathbf{0} \Leftrightarrow\left\{\begin{array} { l } 
{ \mathbf { d } ^ { \text { side } } \times \mathbf { n } _ { \mathrm { w } , Q } ^ { \text { side } } = \mathbf { 0 } } \\
{ \mathbf { n } _ { \mathrm { r } , P } ^ { \text { side } } \times \mathbf { n } _ { \mathrm { w } , Q } ^ { \text { side } } = \mathbf { 0 } }
\end{array} \Leftrightarrow \left\{\begin{array}{l}
\mathbf{d}^{\text {side }} \cdot \mathbf{t}_{\mathrm{w}, \mathrm{u}, Q}^{\text {side }}=0 \\
\mathbf{d}^{\text {side }} \cdot \mathbf{t}_{\mathrm{w}, \mathrm{s}, Q}^{\text {side }}=0 \\
\mathbf{n}_{\mathrm{r}, P}^{\text {side }} \cdot \mathbf{t}_{\mathrm{w}, \mathrm{u}, Q}^{\text {side }}=0 \\
\mathbf{n}_{\mathrm{r}, P}^{\text {side }} \cdot \mathbf{t}_{\mathrm{w}, \mathrm{s}, Q}^{\text {side }}=0
\end{array}\right.\right. \\
& \mathbf{F}_{\mathrm{nl}}\left(s_{\mathrm{r}, P}^{\text {side }}, u_{\mathrm{r}, P}^{\text {side }}, s_{\mathrm{w}, Q}^{\text {side }}, u_{\mathrm{w}, Q}^{\text {side }}\right)=\mathbf{0} \Leftrightarrow\left\{\begin{array} { l } 
{ \mathbf { d } ^ { \text { side } } \times \mathbf { n } _ { \mathrm { r } , P } ^ { \text { side } } = \mathbf { 0 } } \\
{ \mathbf { n } _ { \mathrm { w } , Q } ^ { \text { side } } \times \mathbf { n } _ { \mathrm { r } , P } ^ { \text { side } } = \mathbf { 0 } }
\end{array} \Leftrightarrow \left\{\begin{array}{l}
\mathbf{d}^{\text {side }} \cdot \mathbf{t}_{\mathrm{r}, \mathrm{u}, P}^{\text {side }}=0 \\
\mathbf{d}^{\text {side }} \cdot \mathbf{t}_{\mathrm{r}, \mathrm{s}, P}^{\text {side }}=0 \\
\mathbf{n}_{\mathrm{w}, Q}^{\text {side }} \cdot \mathbf{t}_{\mathrm{r}, \mathrm{u}, P}^{\text {side }}=0 \\
\mathbf{n}_{\mathrm{w}, Q}^{\text {side }} \cdot \mathbf{t}_{\mathrm{r}, \mathrm{s}, P}^{\text {side }}=0
\end{array}\right.\right.
\end{aligned}
$$


Each one of these sets of nonlinear equations can be solved by iterative methods, such as NewtonRaphson, to obtain the set of surface parameters, $s_{\mathrm{r}, P}^{\text {side }}, u_{\mathrm{r}, P}^{\text {side }}, s_{\mathrm{w}, Q}^{\text {side }}$ and $u_{\mathrm{w}, Q}^{\text {side }}$, that satisfies the minimum distance condition. The solution of this problem returns two potential contact points, one in each surface, however, the occurrence of contact must be properly checked. Thus, three different scenarios can be identified according to the relative orientation of vectors $\mathbf{n}_{\mathrm{r}, P}^{\text {side }}$ and $\mathbf{d}^{\text {side }}$ , as schematized in Fig. 5. This verification can be performed by evaluating the inner product between those vectors. If $\mathbf{n}_{\mathrm{r}, P}^{\text {side }} \cdot \mathbf{d}^{\text {side }}>0$, there is no contact, as in Fig. 5(a). In the case that $\mathbf{n}_{\mathrm{r}, P}^{\text {side }} \cdot \mathbf{d}^{\text {side }}=0$, the two surfaces are locally tangent, which means there is contact with no penetration, shown in Fig. 5(b). Finally, if $\mathbf{n}_{\mathrm{r}, P}^{\text {side }} \cdot \mathbf{d}^{\text {side }}<0$, the contact occurs and there is a virtual penetration or indentation of the surfaces, as observed in Fig. 5(c).

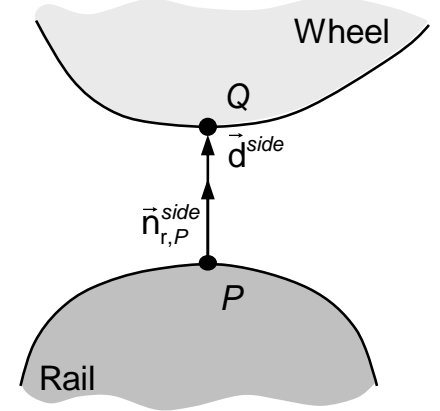

(a)

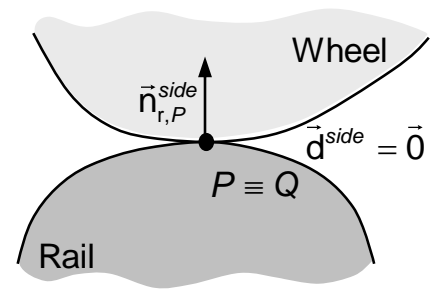

(b)

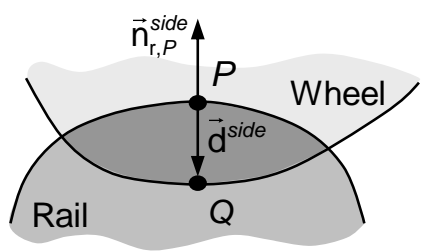

(c)

Fig. 5 Simplified representation of possible scenarios between convex wheel and rail profiles:

(a) No contact; (b) Contact with no penetration; (c) Contact with penetration.

In the presence of two convex surfaces together with an appropriate initial approximation of the surface parameters, this methodology has proven to be effective and robust $[3,41]$. However, actual wheels and rails may interact in a conformal region, where one of the surfaces has negative curvature. In this case, it may be not possible to find a solution for the geometric problem given by Eq. (30) or (31). To clarify this point, a scenario in which the wheel and rail are aligned (i.e., without yaw) is used as a demonstrative example. Since both elements are aligned, it is easy to identify the plane where the contact points can be located, that is, transversal to the rail surface and passing through the wheel axis, as represented in Fig. 6. Hence, the search for potential contact points can be simplified, since for this plane the longitudinal surface parameter of the rail $\left(s_{\mathrm{r}}\right)$ and the angular surface parameter of the wheel $\left(s_{\mathrm{w}}\right)$ are constant. Thus, the contact detection problem is reduced to the finding of the lateral surface parameters $\left(u_{\mathrm{r}}\right.$ and $\left.u_{\mathrm{w}}\right)$ that verify the contact constraints.

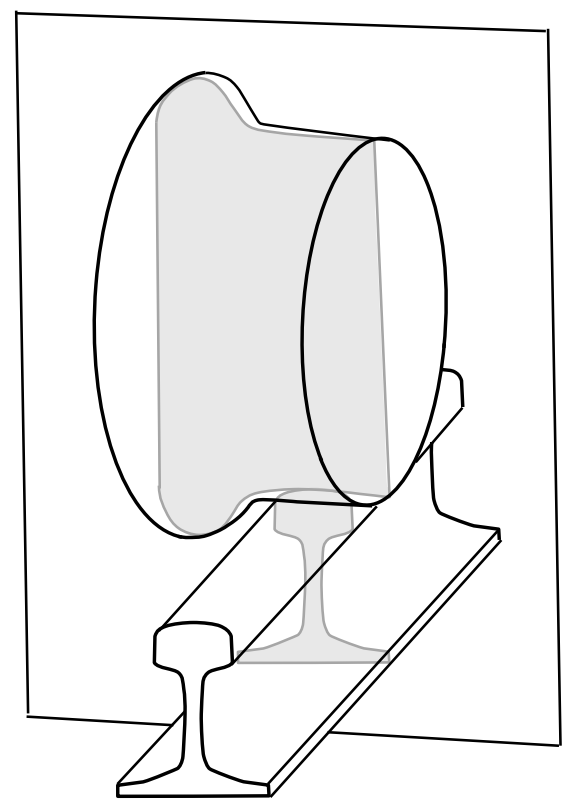

Fig. 6 Representation of a contact scenario in which the wheel and rail are aligned and the plane that contains the contact points. 
In order to clarify the abovementioned point, the S1002 wheel profile and the UIC50 rail profile are utilized. The two cases are depicted in Figures 7(a)-(b), where the top of the rail contacts the wheel tread, non-conformal contact, and the rail corner contacts the tread/flange concordance zone, conformal contact. Then, the vector $\mathbf{F}_{\mathrm{nl}}$, which represents the residual of the contact equations, is evaluated for all possible combinations of the lateral surface parameters in the contact zone and its neighbourhood. Figures 7(c)-(d) present a colormap of the norm of $\mathbf{F}_{\mathrm{nl}}$ as function of both lateral surface parameters, where a null value represents the contact point. For the nonconformal case, it can be observed in Fig. 7(c) that only one well-defined minimum exists which marked in red. Regarding the conformal scenario shown in Fig. 7(d), several combinations of the wheel and rail parameters spread through the domain closely satisfy the contact equations, meaning that the convergence for an optimal solution is not ensured. Therefore, an alternative methodology is required to solve the contact detection between wheel and rail surfaces when nonconvex profiles are considered.

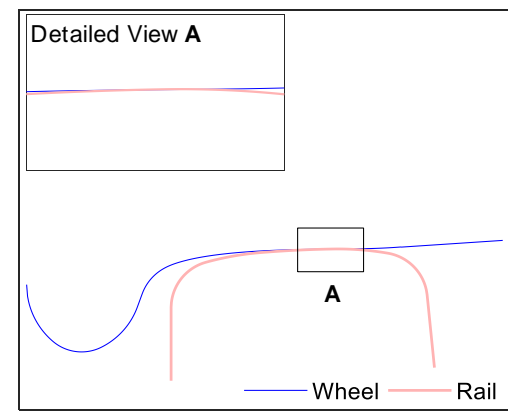

(a)

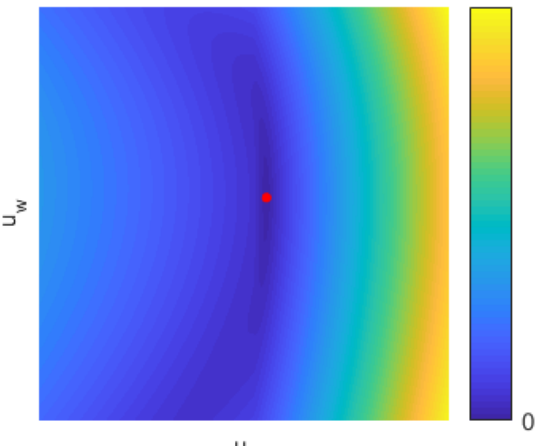

(c)

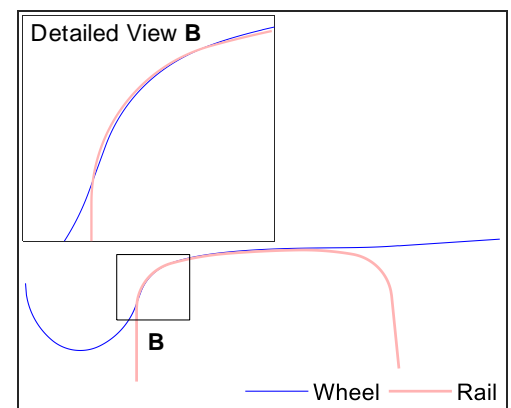

(b)

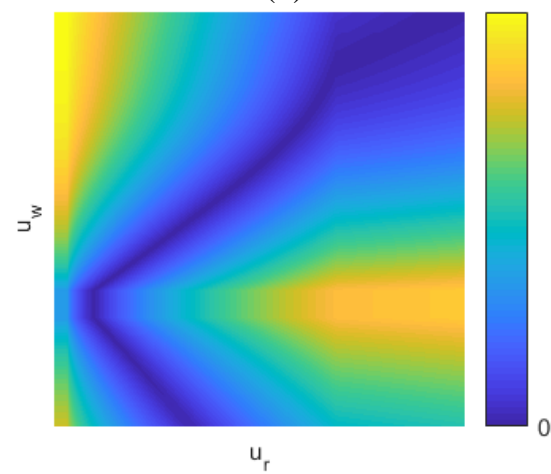

(d)

Fig. 7 Analysis of the existence of solution of the minimum distance problem for a non-conformal and conformal 2D cases: (a)-(b) wheel-rail relative position, and (c)-(d) norm of the residual of contact equations.

\subsection{Proposed approach}

With the purpose to overcome the demonstrated limitations of the minimum distance method to identify the contact points for concave surfaces, a novel approach to deal with the contact detection between general wheel and rail profiles is proposed here. The general idea of this methodology is to define the wheel surface as a set of strips or slices [71,72] that represents circumferences with different radii, according to the wheel profile, as it is schematically represented in Fig. 8(a). Thus, the contact search can be performed between each strip of the wheel and the rail surface. Since the rail has a convex surface, a pair of points that satisfies the minimum distance condition between a wheel strip and the surface is guaranteed. For a given wheel lateral parameter, $u_{\mathrm{w}}$, which defines a strip, the system of the contact constraint equations of Eqs. (30) and (31) is reduced to three equations, that is

$$
\mathbf{F}_{\mathrm{nl}}\left(s_{\mathrm{r}, P}^{\text {side }}, u_{\mathrm{r}, P}^{\text {side }}, s_{\mathrm{w}, Q}^{\text {side }}\right)=\mathbf{0} \Leftrightarrow\left\{\begin{array}{c}
\mathbf{d}^{\text {side }} \cdot \mathbf{t}_{\mathrm{r}, \mathrm{s}, P}^{\text {side }}=0 \\
\mathbf{d}^{\text {side }} \cdot \mathbf{t}_{\mathrm{r}, \mathrm{s}, P}=0 \\
\mathbf{n}_{\mathrm{r}, P}^{\text {side }} \cdot \mathbf{t}_{\mathrm{w}, \mathrm{s}, Q}^{\text {side }}=0
\end{array}\right.
$$


Similar to Eqs. (30) and (31), an iterative method to solve the system of nonlinear equations defined by Eq. (32) is required, namely the Newton-Raphson method. The distance between the potential points of contact obtained for each strip represents either the penetration, in case of contact, or the separation, otherwise, as schematized in Fig. 8(b). To find the contact points, the parameter $u_{\mathrm{w}, Q}^{\text {side }}$, which identifies the wheel strip, that corresponds to the largest penetration value is determined based on an optimization approach. It must be highlighted that for the evaluation of a given strip, Eq. (32) has to be solved, then, the contact must be checked, as previously described, and depicted in Fig. 5, being the penetration given by

$$
\delta=\left\|\mathbf{d}^{\text {side }}\right\|
$$

If the strip is not in contact with the rail surface, $\delta$ denotes the separation distance.

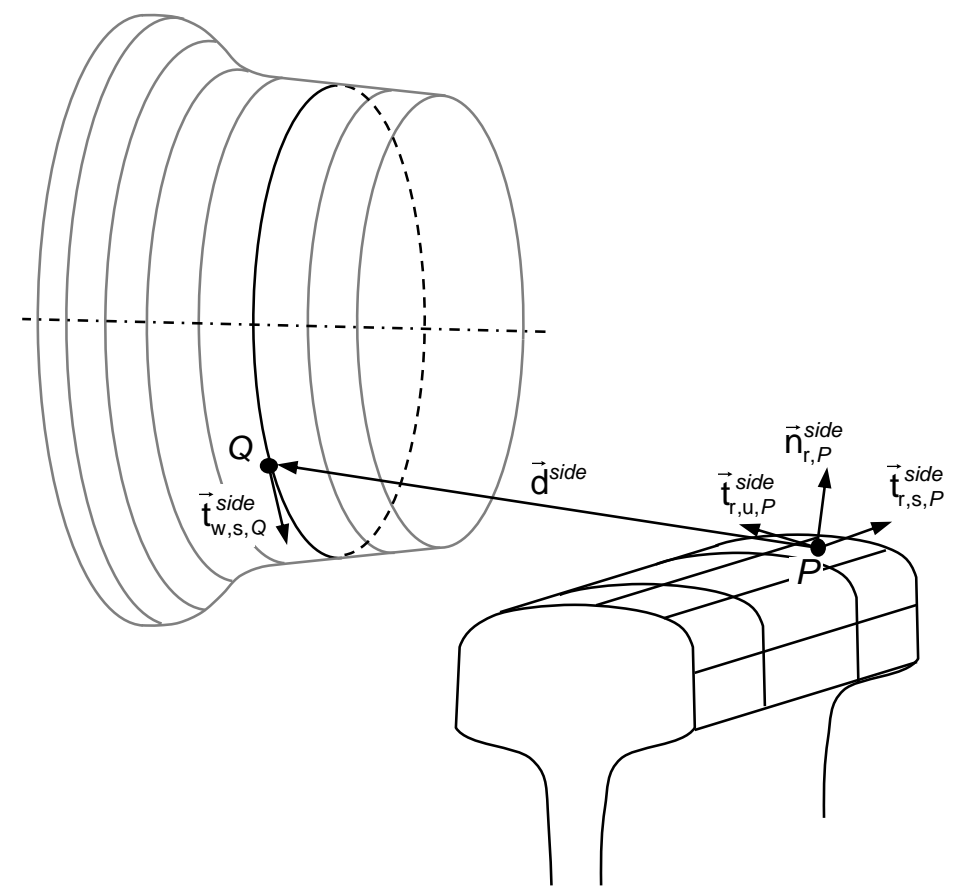

(a)

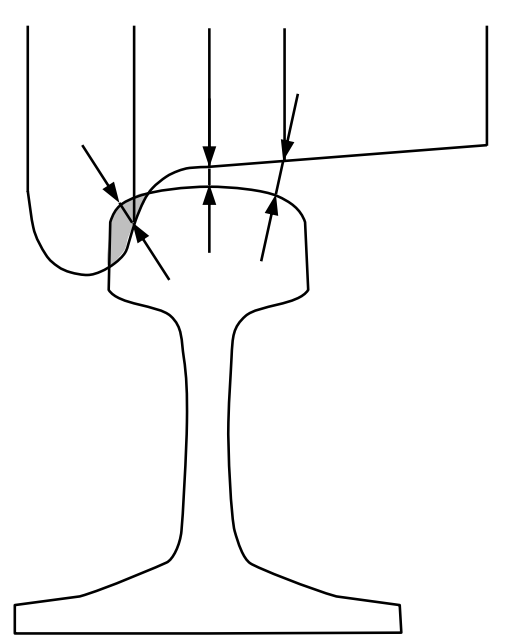

(b)

Fig. 8 Representation of the wheel divided into strips: (a) Contact evaluation between two arbitrary points; (b) Schematic 2D representation of the resultant candidate points.

The performance of this methodology has been demonstrated for wheel-rail static cases [56]. However, for each wheel-rail pair, solving Eq. (32) with respect to several wheel strips to find the maximum penetration point leads to dynamic simulations that involve a higher computational cost. Thus, it is required to ensure an effective usability of this methodology, namely reducing the size of the problem to be solved in each step. One reasonable assumption to simplify the contact search is to consider that the rail is locally straight, i.e., the orientation of the rail coordinate frame is fixed during each contact search. This is a suitable hypothesis, because the curvature of the rail path is very large when compared to the size of the local contact zone. In the contact detection, the first step is to find the position and orientation of the rail local coordinate system to be used for the contact search, which varies along the rail longitudinal parameter, $s_{\mathrm{r}}^{\text {side }}$, as represented for the right rail in Fig. 9. Here, the point of the rail path, which is closest to the wheel center, must correspond to the rail coordinate frame. It must be found the value of parameter $s_{\mathrm{r}}^{\text {side }}$ that minimizes the distance between the wheel and rail profiles represented by vector $\mathbf{d}_{\mathrm{rw}}^{\text {side }}$, shown in Fig. 9, and evaluated as

$$
\mathbf{d}_{\mathrm{rw}}^{\text {side }}=\mathbf{r}_{\mathrm{r}}^{\text {side }}-\mathbf{r}_{\mathrm{w}}^{\text {side }}
$$

in which

$$
\mathbf{r}_{\mathrm{w}}^{\text {side }}=\mathbf{r}_{\mathrm{ws}}+\mathbf{h}_{\mathrm{w}}^{\text {side }}
$$


The minimum distance between the wheel and rail can be obtained when the distance vector and tangent vector are perpendicular to each other, and, therefore satisfying the condition

$$
\mathbf{d}_{\mathrm{rw}}^{\text {side }} \cdot \mathbf{t}_{\mathrm{r}}^{\text {side }}=0
$$

This condition is function of the rail longitudinal parameter, and it can be solved in an efficient manner using the parameter value obtained in the previous time step of the time integration as initial guess. Hence, the obtained $s_{\mathrm{r}}^{\text {side }}$ is utilized to determine the rail profile location, $\mathbf{r}_{\mathrm{r}}^{\text {side }}$, and orientation, $\mathbf{A}_{\mathrm{r}}^{\text {side }}$, for the remaining steps of the contact search.

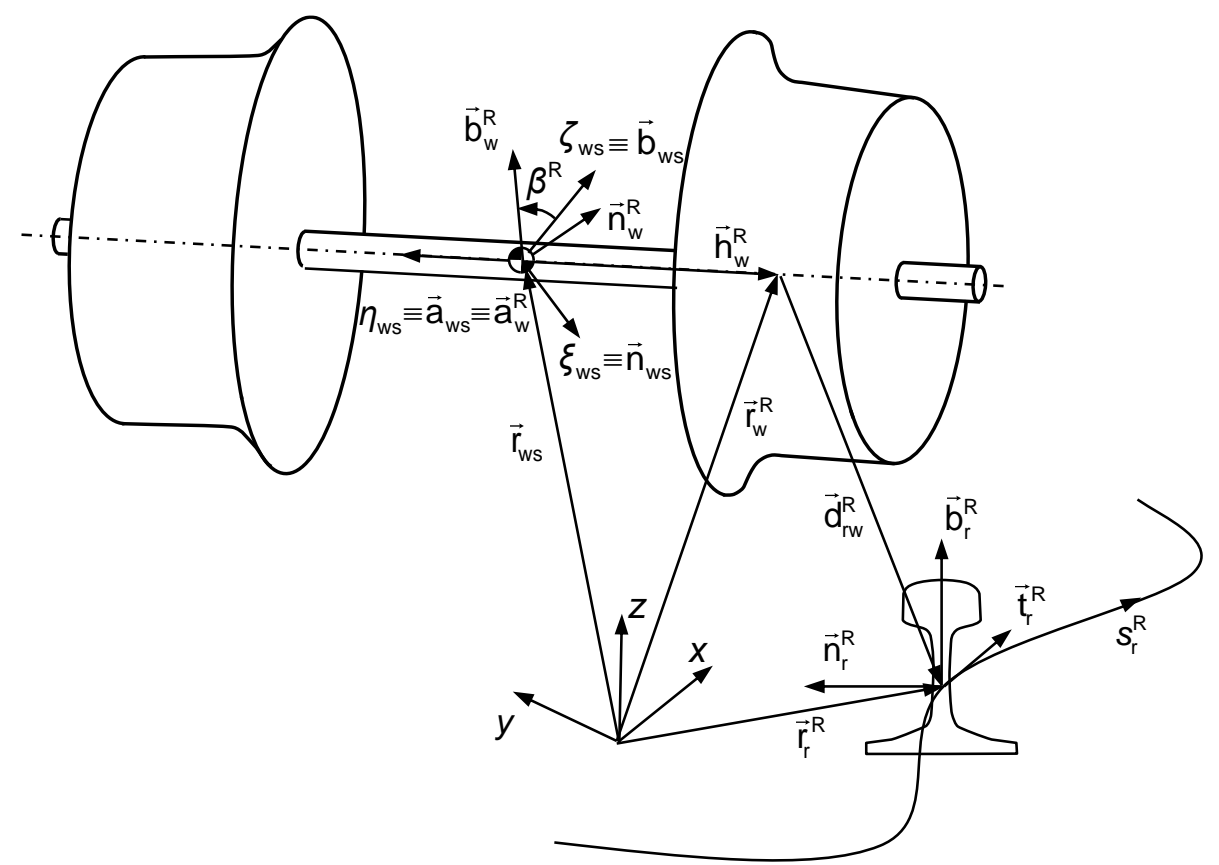

Fig. 9 Representation of the determination of both wheel and rail local coordinate systems.

Subsequently, a wheel coordinate system aligned with the rail coordinate system is determined, which allows a more immediate rotation from the wheel coordinate system to the rail coordinate system. So far, the wheel orientation is defined by the wheelset transformation matrix, $\mathbf{A}_{\mathrm{ws}}$, as in Eq. (7), which is decomposed into three unit vectors that represent the axes of the wheelset local frame, as displayed in Fig. 9, that is,

$$
\mathbf{A}_{\mathrm{ws}}=\left[\begin{array}{lll}
\mathbf{n}_{\mathrm{ws}} & \mathbf{a}_{\mathrm{ws}} & \mathbf{b}_{\mathrm{ws}}
\end{array}\right]
$$

where $\mathbf{n}_{\mathrm{ws}}$ is the normal unit vector along the $\xi_{\mathrm{ws}}$ axis, $\mathbf{a}_{\mathrm{ws}}$ denotes the axial unit vector along the $\eta_{\mathrm{ws}}$ axis, and $\mathbf{b}_{\mathrm{ws}}$ represents the binormal unit vector along the $\zeta_{\mathrm{ws}}$ axis. With the intent to obtain a wheel coordinate system aligned with the rail frame, this coordinate system is rotated about the wheelset axis a given angle $\beta^{\text {side }}$, as depicted in Fig. 9 for the right wheel. The novel transformation matrix of the wheel is defined as

$$
\mathbf{A}_{\mathrm{w}}^{\text {side }}=\left[\begin{array}{lll}
\mathbf{n}_{\mathrm{w}}^{\text {side }} & \mathbf{a}_{\mathrm{w}}^{\text {side }} & \mathbf{b}_{\mathrm{w}}^{\text {side }}
\end{array}\right]
$$

in which

$$
\begin{gathered}
\mathbf{a}_{\mathrm{w}}^{\text {side }}=\mathbf{a}_{\mathrm{ws}} \\
\mathbf{b}_{\mathrm{w}}^{\text {side }}=\frac{\mathbf{t}_{\mathrm{r}}^{\text {side }} \times \mathbf{a}_{\mathrm{w}}^{\text {side }}}{\left\|\mathbf{t}_{\mathrm{r}}^{\text {side }} \times \mathbf{a}_{\mathrm{w}}^{\text {side }}\right\|} \\
\mathbf{n}_{\mathrm{w}}^{\text {side }}=\mathbf{a}_{\mathrm{w}}^{\text {side }} \times \mathbf{b}_{\mathrm{w}}^{\text {side }}
\end{gathered}
$$


The wheel transformation matrix allows the wheel angular coordinate, $s_{\mathrm{w}}^{\text {side }}$, to be measured from the same position relatively to rail. This means that when $s_{\mathrm{w}, Q}^{\text {side }}=0$, point $Q$ is located in the lower part of the wheel, since this coordinate system does not follow the wheel rolling motion.

Due to the introduction of the concept of wheel transformation matrix, the Eqs. (7), (19), (21) and (24) can be rewritten, respectively, as

$$
\begin{aligned}
\mathbf{r}_{\mathrm{w}, Q}^{\text {side }} & =\mathbf{A}_{\mathrm{w}}^{\text {side }} \mathbf{A}_{\mathrm{w}, \mathrm{s}}^{\text {side }} \mathbf{r}_{\mathrm{w}, Q, \mathrm{w}}^{\text {side }} \\
\mathbf{t}_{\mathrm{w}, \mathrm{s}, Q}^{\text {side }} & =\mathbf{A}_{\mathrm{w}}^{\text {side }} \mathbf{A}_{\mathrm{w}, \mathrm{s}}^{\text {side }} \mathbf{t}_{\mathrm{w}, \mathrm{s}, Q, \mathrm{w}}^{\text {side }} \\
\mathbf{t}_{\mathrm{w}, \mathrm{u}, Q}^{\text {side }} & =\mathbf{A}_{\mathrm{w}}^{\text {side }} \mathbf{A}_{\mathrm{w}, \mathrm{s}}^{\text {side }} \mathbf{t}_{\mathrm{w}, \mathrm{u}, Q, \mathrm{w}}^{\text {side }} \\
\mathbf{n}_{\mathrm{w}, Q}^{\text {side }} & =\mathbf{A}_{\mathrm{w}}^{\text {side }} \mathbf{A}_{\mathrm{w}, \mathrm{s}}^{\text {side }} \mathbf{n}_{\mathrm{w}, Q, \mathrm{w}}^{\text {side }}
\end{aligned}
$$

Based on the relation between the wheel and rail coordinate systems, the roll angle, $\varphi$, and the yaw angle, $\alpha$, are obtained through the successive rotation of the axial unit vector of the wheel, as displayed in Fig. 10. First, the vector $\mathbf{a}_{\mathrm{w}}^{\text {side }}$ must be converted to rail local coordinates as

$$
\mathbf{a}_{\mathrm{w}, \mathrm{r}}^{\text {side }}=\mathbf{A}_{\mathrm{r}}^{\text {side }-1} \mathbf{a}_{\mathrm{w}}^{\text {side }}
$$

Then, the roll angle can be evaluated as

$$
\varphi^{\text {side }}=\arctan \left(\frac{a_{\mathrm{w}, \mathrm{r}, 3}^{\text {side }}}{a_{\mathrm{w}, \mathrm{r}, 2}^{\text {side }}}\right)
$$

in which the last element of the subscript corresponds to the respective element of the vector. Thus, the rotation matrix relative to the roll angle can be expressed as

$$
\mathbf{R}_{\varphi}^{\text {side }}=\left[\begin{array}{ccc}
1 & 0 & 0 \\
0 & \cos \left(\varphi^{\text {side }}\right) & -\sin \left(\varphi^{\text {side }}\right) \\
0 & \sin \left(\varphi^{\text {side }}\right) & \cos \left(\varphi^{\text {side }}\right)
\end{array}\right]
$$

Subsequently, to determine the axial vector without roll in the local rail coordinate system, the rail is rotated the symmetric of the roll angle, i.e.,

$$
\mathbf{a}_{\mathrm{w}, \mathrm{r}, \varphi}^{\text {side }}=\mathbf{R}_{-\varphi}^{\text {side }} \mathbf{a}_{\mathrm{w}, \mathrm{r}}^{\text {side }}
$$

Hence, vector $\mathbf{a}_{\mathrm{w}, \mathrm{r}, \varphi}^{\text {side }}$ is used to determine the yaw angle as

$$
\alpha^{\text {side }}=\arctan \left(-\frac{a_{\mathrm{w}, \mathrm{r}, \varphi, 1}^{\text {side }}}{a_{\mathrm{w}, \mathrm{r}, \varphi, 2}^{\text {side }}}\right)
$$

In a similar manner to the roll motion, the rotation matrix regarding the yaw angle is written as

$$
\mathbf{R}_{\alpha}^{\text {side }}=\left[\begin{array}{ccc}
\cos \left(\alpha^{\text {side }}\right) & -\sin \left(\alpha^{\text {side }}\right) & 0 \\
\sin \left(\alpha^{\text {side }}\right) & \cos \left(\alpha^{\text {side }}\right) & 0 \\
0 & 0 & 1
\end{array}\right]
$$

It must be noted that the roll and yaw angles are associated with the relative position of each wheel and the rail, therefore, they are separately calculated for the left and right wheels. 


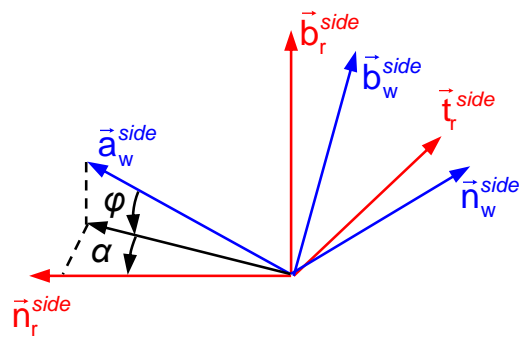

Fig. 10 Representation of the rotation of the wheel coordinate system to determine roll and yaw angles.

One of the constraints to find the contact points concerns the parallelism between both normal vectors. Since the rail is considered to be locally straight, the normal unit vector to the surface must be always in the plane formed by $\mathbf{n}_{\mathrm{r}}^{\text {side }}$ and $\mathbf{b}_{\mathrm{r}}^{\text {side }}$, regardless the rail lateral coordinate. This implies that the normal unit vector to the wheel surface is also on the referred plane, meaning that the first element of this vector in the rail local coordinate system is zero, i.e.,

$$
n_{\mathrm{w}, Q, \mathrm{r}, 1}^{\text {side }}=0
$$

Furthermore, the coordinates of a vector defined in the wheel coordinate system correlate to the rail coordinate system through the two rotations represented in Fig. 10. Therefore, the normal unit vector to the wheel surface is given in the rail coordinate system as

$$
\mathbf{n}_{\mathrm{w}, Q, \mathrm{r}}^{\text {side }}=\mathbf{R}_{\varphi}^{\text {side }} \mathbf{R}_{\alpha}^{\text {side }} \mathbf{A}_{\mathrm{w}, \mathrm{s}}^{\text {side }} \mathbf{n}_{\mathrm{w}, Q, \mathrm{w}}^{\text {side }}
$$

By introducing Eqs. (9), (25), (48) and (51), Eq. (53) is rewritten for the left and right sides, respectively, as

$$
\begin{gathered}
-\mathrm{c}\left(\gamma_{\mathrm{w}, Q}^{\mathrm{L}}\right) \mathrm{s}\left(s_{\mathrm{w}, Q}^{\mathrm{L}}\right) \mathrm{c}\left(\alpha^{\mathrm{L}}\right)-\mathrm{s}\left(\gamma_{\mathrm{w}, Q}^{\mathrm{L}}\right) \mathrm{s}\left(\alpha^{\mathrm{L}}\right) \\
\mathbf{n}_{\mathrm{w}, \mathrm{r}}^{\mathrm{L}}=\left[\begin{array}{c}
\mathrm{c}\left(\gamma_{\mathrm{w}, Q}^{\mathrm{L}}\right) \mathrm{s}\left(s_{\mathrm{w}, Q}^{\mathrm{L}}\right) \mathrm{s}\left(\alpha^{\mathrm{L}}\right) \mathrm{c}\left(\varphi^{\mathrm{L}}\right)+\mathrm{s}\left(\gamma_{\mathrm{w}, Q}^{\mathrm{L}}\right) \mathrm{c}\left(\alpha^{\mathrm{L}}\right) \mathrm{c}\left(\varphi^{\mathrm{L}}\right)+\mathrm{s}\left(\varphi^{\mathrm{L}}\right) \mathrm{c}\left(\gamma_{\mathrm{w}, Q}^{\mathrm{L}}\right) \mathrm{c}\left(s_{\mathrm{w}, Q}^{\mathrm{L}}\right) \\
-\mathrm{c}\left(\gamma_{\mathrm{w}, Q}^{\mathrm{L}}\right) \mathrm{s}\left(s_{\mathrm{w}, Q}^{\mathrm{L}}\right) \mathrm{s}\left(\alpha^{\mathrm{L}}\right) \mathrm{s}\left(\varphi^{\mathrm{L}}\right)+\mathrm{s}\left(\gamma_{\mathrm{w}, Q}^{\mathrm{L}}\right) \mathrm{c}\left(\alpha^{\mathrm{L}}\right) \mathrm{s}\left(\varphi^{\mathrm{L}}\right)-\mathrm{c}\left(\gamma_{\mathrm{w}, Q}^{\mathrm{L}}\right) \mathrm{c}\left(s_{\mathrm{w}, Q}^{\mathrm{L}}\right) \mathrm{c}\left(\varphi^{\mathrm{L}}\right)
\end{array}\right] \\
\mathrm{c}\left(\gamma_{\mathrm{w}, Q}^{\mathrm{R}}\right) \mathrm{s}\left(s_{\mathrm{w}, Q}^{\mathrm{R}}\right) \mathrm{c}\left(\alpha^{\mathrm{R}}\right)+\mathrm{s}\left(\gamma_{\mathrm{w}, Q}^{\mathrm{R}}\right) \mathrm{s}\left(\alpha^{\mathrm{R}}\right) \\
\mathbf{n}_{\mathrm{w}, Q, \mathrm{r}}^{\mathrm{R}}=\left[\begin{array}{c}
\mathrm{c}\left(\gamma_{\mathrm{w}, Q}^{\mathrm{R}}\right) \mathrm{s}\left(s_{\mathrm{w}, Q}^{\mathrm{R}}\right) \mathrm{s}\left(\alpha^{\mathrm{R}}\right) \mathrm{c}\left(\varphi^{\mathrm{R}}\right)-\mathrm{s}\left(\gamma_{\mathrm{w}, Q}^{\mathrm{R}}\right) \mathrm{c}\left(\alpha^{\mathrm{R}}\right) \mathrm{c}\left(\varphi^{\mathrm{R}}\right)+\mathrm{s}\left(\varphi^{\mathrm{R}}\right) \mathrm{c}\left(\gamma_{\mathrm{w}, Q}^{\mathrm{R}}\right) \mathrm{c}\left(s_{\mathrm{w}, Q}^{\mathrm{R}}\right) \\
\mathrm{c}\left(\gamma_{\mathrm{w}, Q}^{\mathrm{R}}\right) \mathrm{s}\left(s_{\mathrm{w}, Q}^{\mathrm{R}}\right) \mathrm{s}\left(\alpha^{\mathrm{R}}\right) \mathrm{s}\left(\varphi^{\mathrm{R}}\right)-\mathrm{s}\left(\gamma_{\mathrm{w}, Q}^{\mathrm{R}}\right) \mathrm{c}\left(\alpha^{\mathrm{R}}\right) \mathrm{s}\left(\varphi^{\mathrm{R}}\right)-\mathrm{c}\left(\gamma_{\mathrm{w}, Q}^{\mathrm{R}}\right) \mathrm{c}\left(s_{\mathrm{w}, Q}^{\mathrm{R}}\right) \mathrm{c}\left(\varphi^{\mathrm{R}}\right)
\end{array}\right]
\end{gathered}
$$

in which 's' and ' $c$ ' denote the sine and cosine functions, respectively, for sake of simplicity. By applying the constraint given by Eq. (52) to Eqs. (54) and (55), the following condition can be written for both left and right sides as

$$
\sin \left(s_{\mathrm{w}, Q}^{\text {side }}\right)=-\frac{\sin \left(\gamma_{\mathrm{w}, Q}^{\text {side }}\right) \sin \left(\alpha^{\text {side }}\right)}{\cos \left(\gamma_{\mathrm{w}, Q}^{\text {side }}\right) \cos \left(\alpha^{\text {side }}\right)}
$$

Through some mathematical manipulation, and introducing Eq. (23), yields

$$
s_{\mathrm{w}, Q}^{\text {side }}=\arcsin \left(-\tan \left(\alpha^{\text {side }}\right) f_{\mathrm{w}, Q}^{\text {side }}\right)
$$

Thus, it is possible to conclude that the angular coordinate of the wheel surface that allows the parallelism between the wheel and rail normal vectors can be analytically calculated as a function of the lateral surface parameter of the wheel, $u_{\mathrm{w}, Q}^{\text {side }}$, and the yaw angle, $\alpha^{\text {side }}$. This represents a significant gain in terms of efficiency, since this parameter does not need to be obtained when solving the contact conditions defined by Eq. (32). In that sense, Since the wheel strip is a full circumference, Eq. (57) returns two solutions from which only the one close to the rail is considered Hence, there is only one potential contact point for each wheel lateral coordinate, and the set of wheel potential 
contact points constitutes a three-dimensional curve. In order to check the existence of contact, this curve is projected onto the rail cross-section and the intersections between this curve and the rail profile represent zones of penetration and, consequently, contact. Then, each of these zones represents a different contact patch, and their intersections indicate the lower and upper bounds of the interpenetration zone, $u_{\mathrm{w}, Q, \text { lower }}^{\text {side }}$ and $u_{\mathrm{w}, Q \text {,upper }}^{\text {side }}$. The contact resolution is treated separately for each patch. Finally, if these curves do not intersect, there is no contact between the wheel and rail.

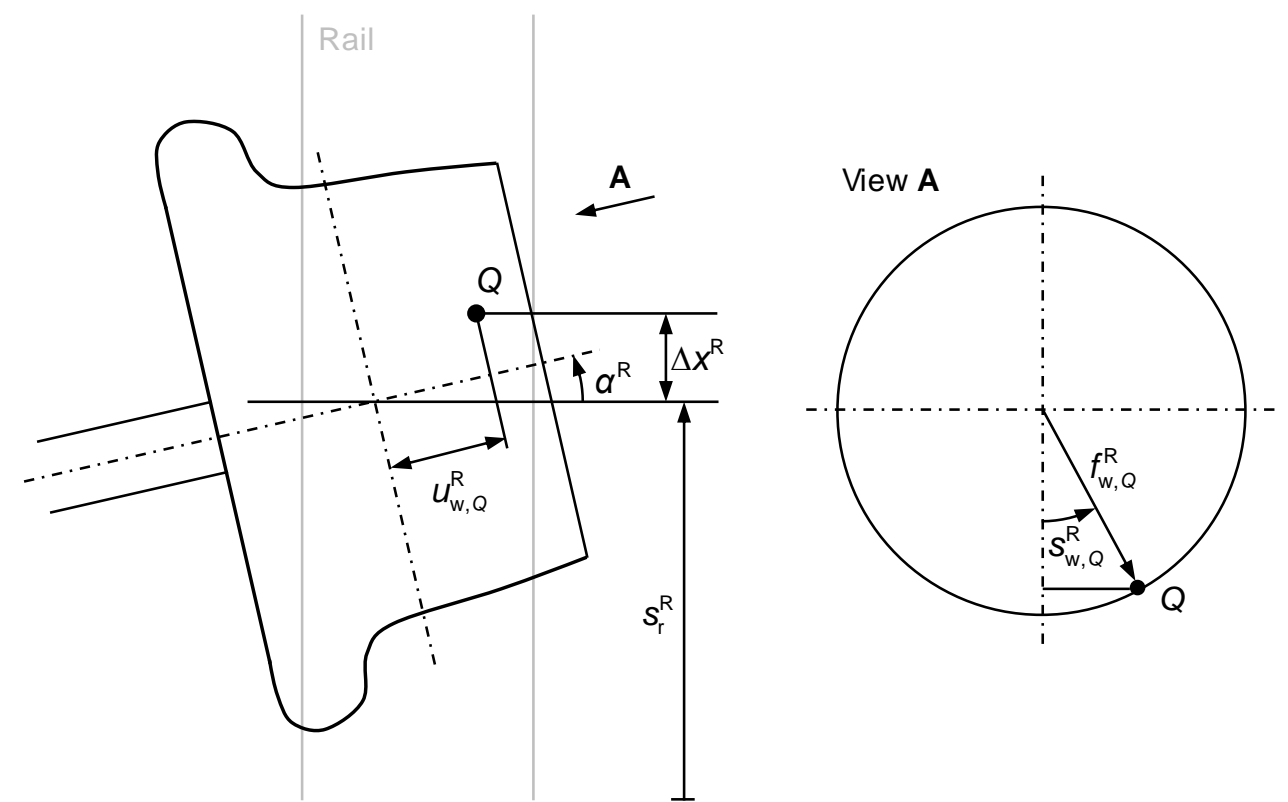

Fig. 11 Representation of the increment of the location of the contact point in the rail longitudinal direction.

Another requirement of the contact condition is that the distance vector between wheel and rail contact points and the normal unit vector to the rail surface must be parallel. Thus, for a given wheel lateral position $u_{\mathrm{w}, Q}^{\text {side }}$, using Eq. (57) and, then, Eq. (42), the position vector of point $Q$ is calculated. Since the distance vector is given by Eq. (29) and the normal unit vector to the rail is within the plane formed by $\mathbf{n}_{\mathrm{r}}^{\text {side }}$ and $\mathbf{b}_{\mathrm{r}}^{\text {side }}$, it is mandatory that the wheel and rail contact points have the same coordinate along the rail tangential direction. This coordinate differs from the rail longitudinal parameter obtained through the solution of Eq. (36) due to the existence of a yaw angle, as schematized in Fig. 11. Therefore, by considering the yaw angle and the wheel lateral coordinate, the increment of the location of the contact point in the rail longitudinal direction is determined following the representation of Fig. 11 for the right side, as

$$
\Delta x^{\mathrm{R}}=u_{\mathrm{w}, Q}^{\mathrm{R}} \sin \left(\alpha^{\mathrm{R}}\right)+\left|f_{\mathrm{w}, Q}^{\mathrm{R}}\right| \sin \left(s_{\mathrm{w}, Q}^{\mathrm{R}}\right) \cos \left(\alpha^{\mathrm{R}}\right)
$$

hence, Eq. (57) is introduced, and (58) is generalized for both sides as

$$
\Delta x^{\mathrm{L}}=\left(\left|f_{\mathrm{w}, Q}^{\mathrm{L}}\right| f_{\mathrm{w}, Q}^{\mathrm{L}}-u_{\mathrm{w}, Q}^{\mathrm{L}}\right) \sin \left(\alpha^{\mathrm{L}}\right) \quad \text { or } \quad \Delta x^{\mathrm{R}}=\left(u_{\mathrm{w}, Q}^{\mathrm{R}}-\left|f_{\mathrm{w}, Q}^{\mathrm{R}}\right| f_{\mathrm{w}, Q}^{\mathrm{R}}\right) \sin \left(\alpha^{\mathrm{R}}\right)
$$

Accordingly, Eq. (3) must be replaced by

$$
\mathbf{r}_{\mathrm{r}, P, \mathrm{r}}^{\text {side }}=\left[\begin{array}{lll}
\Delta x^{\text {side }} & u_{\mathrm{r}, P}^{\text {side }} & f_{\mathrm{r}, P}^{\text {side }}
\end{array}\right]^{\mathrm{T}}
$$

At this stage, the potential contact points depend on the wheel and rail lateral coordinates only, because the wheel angular coordinate and the longitudinal position along the rail can be analytically evaluated. To find the wheel strip that returns the maximum penetration, only the rail lateral coordinate has to be found for each strip. Consequently, instead of solving a system of three non-linear equations as (32), only one equation must be satisfied, that is,

$$
\mathbf{d}^{\text {side }} \cdot \mathbf{t}_{\mathrm{r}, \mathrm{u}, P}^{\text {side }}=0
$$


The substitution of Eq. (32) by Eq. (61) represents a significant simplification in terms of efficiency, which leads to a feasible implementation of this methodology on the dynamic simulation of a railway vehicle running on a track. Overall, this approach consists of finding the wheel lateral parameter that maximizes the penetration between contact points of each contact zone. Therefore, the following optimization problem is formulated

$$
\begin{aligned}
& \min \left(-\delta\left(u_{\mathrm{w}, Q}^{\text {side }}\right)\right) \\
& u_{\mathrm{w}, Q}^{\text {side }} \in\left[\begin{array}{ll}
u_{\mathrm{w}, Q, \text { lower }}^{\text {side }} & u_{\mathrm{w}, Q, \text { upper }}^{\text {side }}
\end{array}\right]
\end{aligned}
$$

Thus, for each strip, the wheel angular parameter is calculated using Eq. (57), the longitudinal position on the rail is computed employing Eq. (59), and the rail lateral parameter is determined by solving Eq. (61). This nonlinear equation is also solved utilizing an iterative root-finding algorithm as the Newton-Raphson method. A more sophisticated method is not required here, since the initial approximation is close enough to the solution.

\section{Evaluation of the contact forces}

A brief description of the normal and tangential contact force models utilized in the context of this work is provided in this section. The contact forces play a key role on the dynamic behavior of the multibody systems with contacts, since they must consider the geometrical and physical properties of the contacting bodies and contribute for the stable resolution of the equations of motion. Bearing this in mind, both the normal and creep forces are evaluated considering Hertzian approaches [73], i.e., the contact patch is assumed to have an elliptical shape and the contact area is estimated based on the properties of the contact point.

\subsection{Normal contact forces}

Regarding the normal contact force evaluation, a Hertzian-based model is utilized here $[32,72,74,75]$. This represents a viscoelastic contact model in which the energy dissipation is taken into account through the coefficient of restitution to make distinction between the contact force during the compression and restitution phases. This modified version of Hertz contact model includes a tolerance velocity to smooth the discontinuity of the contact force in the transition between both phases. Hence, the normal force can be calculated as

$$
f_{\mathrm{n}}= \begin{cases}K \delta^{n} c_{\mathrm{e}} & \dot{\delta} \leq-v_{0} \\ K \delta^{n}\left[c_{\mathrm{e}}+\left(1-c_{\mathrm{e}}\right)\left(3 r^{2}-2 r^{3}\right)\right] & -v_{0}<\dot{\delta}<v_{0} \\ K \delta^{n} & \dot{\delta} \geq v_{0}\end{cases}
$$

in which

$$
r=\frac{\dot{\delta}+v_{0}}{2 v_{0}}
$$

where $K$ represents the generalized contact stiffness, $\delta$ denotes the pseudo-penetration between wheel and rail profiles defined by Eq. (33), $\dot{\delta}$ expresses the penetration velocity, $v_{0}$ is the penetration velocity tolerance, $c_{\mathrm{e}}$ represents the coefficient of restitution, and $n$ is an exponent that defines the degree of nonlinearity, which is typically equal to 1.5 . The penetration velocity quantifies the rate of deformation in the normal contact direction, and can be calculated as

$$
\dot{\delta}=\left(\dot{\mathbf{r}}_{Q}^{\text {side }}-\dot{\mathbf{r}}_{P}^{\text {side }}\right)^{\mathrm{T}} \mathbf{n}_{\mathrm{r}, P}^{\text {side }}
$$

in which $\dot{\mathbf{r}}_{P}^{\text {side }}$ and $\dot{\mathbf{r}}_{Q}^{\text {side }}$ denote the velocity vector of points $P$ and $Q$, respectively. Here, $\dot{\mathbf{r}}_{P}^{\text {side }}$ is null, since the track is assumed to be rigid, while $\dot{\mathbf{r}}_{Q}^{\text {side }}$, according the rigid body theory, is calculated as 


$$
\dot{\mathbf{r}}_{Q}^{\text {side }}=\dot{\mathbf{r}}_{\mathrm{ws}}+\tilde{\boldsymbol{\omega}}_{\mathrm{ws}}\left(\mathbf{h}_{\mathrm{w}}^{\text {side }}+\mathbf{r}_{\mathrm{w}, Q}^{\text {side }}\right)
$$

where $\dot{\mathbf{r}}_{\mathrm{ws}}$ represents the velocity vector of the wheelset, and $\tilde{\boldsymbol{\omega}}_{\mathrm{ws}}$ is the skew-symmetric matrix associated with the angular velocity vector of the wheelset, $\boldsymbol{\omega}_{\mathrm{ws}}$.

In what concerns the generalized contact stiffness, which depends on the local geometry of the contacting bodies and on their material properties, it is evaluated as

$$
K=\frac{4 C_{\delta}}{3\left(h_{\mathrm{w}}+h_{\mathrm{r}}\right) \sqrt{A+B}}
$$

where $A$ and $B$ represent the average curvatures of both surfaces in each principal direction, and can be computed as follows

$$
\begin{aligned}
& A=\left(\kappa_{\mathrm{r}, P}^{\mathrm{s} \text {,side }}+\kappa_{\mathrm{w}, Q}^{\mathrm{s}, \text { side }}\right) / 2 \\
& B=\left(\kappa_{\mathrm{r}, P}^{\mathrm{u} \text {,side }}+\kappa_{\mathrm{w}, Q}^{\mathrm{u} \text {,side }}\right) / 2
\end{aligned}
$$

The parameter $C_{\delta}$ is a function of the ratio $A / B$, which is tabulated in the references [7678]. The terms $h_{\mathrm{w}}$ and $h_{\mathrm{r}}$ are the wheel and rail material parameters, respectively, which can be given as

$$
h_{k}=\frac{1-v_{k}^{2}}{\pi E_{k}} \quad \text { with } \quad k=\mathrm{w}, \mathrm{r}
$$

where $E$ is the Young's modulus, and $v$ represents the Poisson ratio of respective element.

Since the material properties can be considered constant for the wheel and rail pair, this contact model ensures the continuity of the normal force unless there is a major change on the contact curvature between two consecutive time steps.

\subsection{Creep forces}

In the case of pure rolling, no relative motion occurs at the contact point, however, the natural wheel-rail contact leads to creepages, which, in turn, can be split into longitudinal, lateral and spin creepages. Even when the wheelset rolls with no lateral movement, no traction and braking forces, spin creepage is observed, since the contact angle, which is angle between the wheel axis and the plane where the contact patch lies, is not null. Considering the typical shape of the wheel profile, the spin creepage tends to be higher when a contact point moves to the flange since the contact angle increases, leading to more severe creep forces and, hence, wear. The longitudinal, lateral and spin creepages, which are evaluated at the contact point are defined, respectively, as

$$
\begin{aligned}
& v_{x}^{\text {side }}=\frac{\mathbf{v}_{\mathrm{rel}}^{\text {side }} \cdot \mathbf{t}_{\mathrm{w}, \mathrm{s}, Q}^{\text {side }}}{v_{\mathrm{ws}}} \\
& v_{y}^{\mathrm{L}}=\frac{\mathbf{v}_{\mathrm{rel}}^{\mathrm{L}} \cdot \mathbf{t}_{\mathrm{w}, \mathrm{u}, Q}^{\mathrm{L}}}{v_{\mathrm{ws}}} \quad \text { or } \quad v_{y}^{\mathrm{R}}=-\frac{\mathbf{v}_{\mathrm{rel}}^{\mathrm{R}} \cdot \mathbf{t}_{\mathrm{w}, \mathrm{u}, Q}^{\mathrm{R}}}{v_{\mathrm{ws}}} \\
& \phi^{\text {side }}=\frac{\boldsymbol{\omega}_{\mathrm{ws}}{ }^{\mathrm{T}} \mathbf{n}_{\mathrm{r}, P}^{\text {side }}}{v_{\mathrm{ws}}}
\end{aligned}
$$

where $v_{\mathrm{ws}}$ denotes the magnitude of the linear velocity of the wheelset, and $\mathbf{v}_{\text {rel }}^{\text {side }}$ is the vector of the relative velocity in the contact point, which can be calculated as

$$
\mathbf{v}_{\text {rel }}^{\text {side }}=\dot{\mathbf{r}}_{Q}^{\text {side }}-\dot{\mathbf{r}}_{P}^{\text {side }}
$$


The existence of creepages results in the development of creep forces and moment. In this work, the fast algorithm proposed by Polach [79] is utilized, which complies with Hertz theory by also considering an elliptical contact patch being developed based on the Kalker rolling contact theory [80]. Thus, the calculation of the size of contact ellipse is required, for which, according to Hertz theory, the longitudinal and lateral semi-axes can be evaluated, respectively, as

$$
\begin{aligned}
& a=m \sqrt[3]{\frac{3 \pi}{4} \frac{h_{\mathrm{w}}+h_{\mathrm{r}}}{A+B} f_{\mathrm{n}}} \\
& b=n \sqrt[3]{\frac{3 \pi}{4} \frac{h_{\mathrm{w}}+h_{\mathrm{r}}}{A+B} f_{\mathrm{n}}}
\end{aligned}
$$

where $m$ and $n$ are tabulated values [76-78] and can be determined as function of

$$
\theta=\arccos \left(\frac{B-A}{A+B}\right)
$$

According to the Polach's model, the spin creep moment is neglected, and the creep forces are calculated as

$$
\begin{gathered}
f_{x}=f \frac{v_{x}}{v_{C}} \\
f_{y}=f \frac{v_{y}}{v_{C}}+f_{y \mathrm{~S}} \frac{\phi}{v_{C}} \\
m_{z}=0
\end{gathered}
$$

in which $f$ is the resultant tangential contact force caused by the longitudinal and spin creepages, given as

$$
f=-\frac{2 \mu f_{\mathrm{n}}}{\pi}\left(\frac{\varepsilon_{\mathrm{p}}}{1+\varepsilon_{\mathrm{p}}{ }^{2}}+\arctan \left(\varepsilon_{\mathrm{p}}\right)\right)
$$

where $\mu$ represents the coefficient of friction of the pair of materials in contact, and $\varepsilon_{\mathrm{p}}$ is the gradient of tangential stress in the area of adhesion, computed as

$$
\varepsilon_{\mathrm{p}}=\frac{1}{4} \frac{G \pi a b c_{j j}}{\mu f_{\mathrm{n}}} v_{\mathrm{C}}
$$

in which $G$ is the equivalent shear modulus of rigidity of the pair of materials, $c_{j j}$ is a weighted constant based on Kalker coefficients, given as

$$
c_{j j}=\sqrt{\left(c_{11} \frac{v_{y}}{v}\right)^{2}+\left(c_{22} \frac{v_{y}}{v}\right)^{2}}
$$

where $c_{11}$ and $c_{22}$ are, respectively, the longitudinal and lateral creepage coefficients given by Kalker, which are tabulated [80], and obtained as a function of the Poisson's ratio and the ratio of semi-axes of contact ellipse, $a / b$. The variables $v$ and $v_{\mathrm{C}}$ represent, respectively, the magnitude of translational creepage and the modified translational creepage, computed as

$$
\begin{gathered}
v=\sqrt{v_{x}^{2}+v_{y}^{2}} \\
v_{\mathrm{C}}=\sqrt{v_{x}^{2}+v_{y \mathrm{C}}^{2}}
\end{gathered}
$$


in which $v_{y C}$ is the modified lateral creepage that is given by the piecewise function

$$
v_{y C}= \begin{cases}v_{y} & \left|v_{y}+\phi a\right| \leq\left|v_{y}\right| \\ v_{y}+\phi a & \left|v_{y}+\phi a\right|>\left|v_{y}\right|\end{cases}
$$

The spin effect is considered by calculating the lateral tangential force due to the influence of spin creepage, which is included in Eq. (79), as

$$
f_{\mathrm{yS}}=-\frac{9}{16} a \mu f_{\mathrm{n}} k_{\mathrm{M}}\left[1+6.3\left(1-e^{-\frac{a}{b}}\right)\right]
$$

where $k_{\mathrm{M}}$ is computed as

$$
k_{\mathrm{M}}=\left|\varepsilon_{\mathrm{S}}\right|\left(\frac{\delta_{\mathrm{S}}^{3}}{3}-\frac{\delta_{\mathrm{S}}^{2}}{2}+\frac{1}{6}\right)-\frac{1}{3} \sqrt{\left(1-\delta_{\mathrm{S}}\right)^{3}}
$$

in which $\delta_{\mathrm{S}}$ is given as

$$
\delta_{\mathrm{S}}=\frac{\varepsilon_{\mathrm{S}}^{2}-1}{\varepsilon_{\mathrm{S}}^{2}+1}
$$

and $\varepsilon_{\mathrm{S}}$ is defined as

$$
\varepsilon_{\mathrm{S}}=\frac{8}{3} \frac{G b \sqrt{a b}}{\mu f_{\mathrm{n}}} \frac{c_{23} v_{y \mathrm{C}}}{1+6.3\left(1-e^{-\frac{a}{b}}\right)}
$$

where $c_{23}$ is the spin creepage coefficient given by Kalker, which is obtained in a similar manner as the remaining ones [80].

\section{Multibody dynamics formulation}

A general multibody system can be understood as a set of bodies, constrained by kinematic pairs and acted by forces, that can describe large translations and rotations. This is transposed to the field of railway dynamics, in which the vehicle is constituted by a collection of bodies, such as the carbody, bogie frames, axleboxes and wheelsets. In a constrained multibody system, the set of algebraic constraint equation can be written as follows [68]

$$
\boldsymbol{\Phi}(\mathbf{q}, t)=\mathbf{0}
$$

in which $\mathbf{q}$ denotes the vector of the generalized coordinates of the system and $t$ is the time variable. Each kinematic pair contributes with a number of constraint equations equal to the eliminated degrees-of-freedom. In the context of this work, Cartesian coordinates are utilized to describe the equations of motion of a multibody system. Nevertheless, the orientation of each rigid body is given by Euler parameters to avoid singularities [68].

The Newton-Euler equation for a constrained multibody system can be written as

$$
\mathbf{M} \ddot{\mathbf{q}}=\mathbf{g}+\mathbf{g}^{(\mathbf{c})}
$$

where $\mathbf{M}$ represents the mass matrix of the global system, $\ddot{\mathbf{q}}$ denotes the generalized accelerations vector, $\mathbf{g}$ is the vector of external generalized forces, and $\mathbf{g}^{(\mathbf{c})}$ is the vector of reaction forces in the kinematic joints. Differentiating Eq. (91) twice with respect to time, the acceleration constraint equations are obtained. Then, utilizing the Lagrange multipliers technique to describe the reaction forces at the joints, the acceleration constraint equations can be gathered with Eq. (92) resulting in the linear system of equations of motion, 


$$
\left[\begin{array}{cc}
\mathbf{M} & \boldsymbol{\Phi}_{\mathbf{q}}^{T} \\
\boldsymbol{\Phi}_{\mathbf{q}} & \mathbf{0}
\end{array}\right]\left\{\begin{array}{l}
\ddot{\mathbf{q}} \\
\lambda
\end{array}\right\}=\left\{\begin{array}{l}
\mathbf{g} \\
\gamma
\end{array}\right\}
$$

in which $\boldsymbol{\Phi}_{\mathrm{q}}$ represents the Jacobian matrix of the constraints equations, $\gamma$ is the right-hand side vector of the acceleration constraint equations, and $\lambda$ is the vector of Lagrange multipliers, which represents the reaction forces on the ideal joints. It must be noticed that the wheel-rail contact forces calculated according the formulation presented in Section 4 are introduced into the equations of motion (93) as external forces acting upon the wheelsets. Moreover, the primary and secondary suspensions can also be modeled as external forces acting on the bodies they connect.

To assess the motion of the system, Eq. (93) must be solved in each time step to obtain the system's accelerations, which are then integrated over time. Since position and velocity constraint equations are not explicitly used, they are allowed to be violated due to the error introduced by the numerical integration procedure. Therefore, to keep the violation of the constraints acceptable, the Baumgarte stabilization technique is employed here [81,82]. Thus, Eq. (93) can be modified to the following form

$$
\left[\begin{array}{cc}
\mathbf{M} & \boldsymbol{\Phi}_{\mathbf{q}}^{T} \\
\boldsymbol{\Phi}_{\mathbf{q}} & \mathbf{0}
\end{array}\right]\left[\begin{array}{c}
\ddot{\mathbf{q}} \\
\lambda
\end{array}\right\}=\left\{\begin{array}{c}
\mathbf{g} \\
\boldsymbol{\gamma}-2 \alpha \dot{\mathbf{\Phi}}-\beta^{2} \boldsymbol{\Phi}
\end{array}\right\}
$$

where $\alpha$ and $\beta$ are positive values that represent the feedback control parameters for the velocity and position constraint violations $[81,83]$. In this work, both parameters are equal to 5 .

\section{Demonstrative application cases}

This section provides three different application cases to verify the validity and robustness of the methodology proposed for the contact detection between wheel and rail surfaces. Here, a wheelset running on a tangent track, a bogie running on a tangent track and a trailer vehicle running on a curved track are used as demonstrative scenarios [3]. For each application, three different scenarios are compared, namely, (i) convex wheel profiles with the minimum distance method; (ii) convex wheel profiles with the proposed contact detection method; (iii) real wheel profiles with the proposed contact detection method. The convex wheel profiles refer to the modification proposed in Section 2.2, and seen in Fig. 3(b), which eliminates the transition zone between the wheel tread and wheel flange, for which the utilization of the minimum distance method for the contact search is applicable. Therefore, using both contact detection methods with the modified wheel profile, it is possible to assess whether their outcomes are in agreement. Finally, the third scenario allows to verify the suitability and efficiency of the approach presented for realistic wheel profiles.

The multibody model of the ML95 vehicle is used here for the dynamic simulations. The wheel and rail profiles are the S1002 and UIC50, respectively, which are represented in Fig. 7. Both the original and modified wheel profiles are analyzed in detail in Fig. 3. The remaining parameters utilized for the wheel-rail contact model are listed in Table 1. Further details on the multibody model of the vehicle, namely suspension characteristics, inertia properties or relative positions of the bodies, can be found in reference [78].

For the three examples of application, the initial configuration of the multibody models considers a lateral misalignment of $2 \mathrm{~mm}$ to promote the hunting motion of the system. Each multibody model is animated with different initial forward velocity, and the angular velocity of the wheelsets is calculated accordingly considering the nominal wheel radius. Due to the numerical stabilization regarding the wheel-rail contact, the vehicle initial position includes the wheels just above the rails in order for the multibody simulation to be initiated with no contact between the wheel and rail. However, all wheel-rail pairs are in a situation of imminent contact and their interaction initiates less than a millisecond after the beginning of the simulation. Finally, for both bogie and trailer simulations, the initial configuration of the suspension springs includes a proper preload that balances the sprung masses, that is, the carbody and bogie frame. 
Table 1 Parameters for the wheel-rail contact model utilized in the dynamic simulations

\begin{tabular}{ll}
\hline Parameter & Value \\
\hline Nominal wheel radius, $R_{0}$ & $0.43 \mathrm{~m}$ \\
\hline Distance between wheel profiles, $H$ & $1.5 \mathrm{~m}$ \\
\hline Young modulus, $E$ & $206 \mathrm{GPa}$ \\
\hline Poisson ratio, $\boldsymbol{V}$ & 0.296 \\
\hline Coefficient of friction, $\mu$ & 0.25 \\
\hline Coefficient of restitution, $c_{\mathrm{e}}$ & 0.75 \\
\hline Tolerance velocity, $v_{0}$ & $0.1 \mathrm{~m} / \mathrm{s}$ \\
\hline Track gauge & $1.435 \mathrm{~m}$ \\
\hline Rail cant & $1 / 20$ \\
\hline
\end{tabular}

The simulations are performed in an in-house MATLAB code devoted to the dynamic analysis of spatial multibody systems, called MUBODYNA, in which the methodologies presented for wheel-rail contact model are implemented. The numerical integration process is performed using to the 'ode45' solver, and the optimization problem depicted in Eq. (62) is solved using 'fmincon'. The utilized settings for both functions are listed in Table 2.

Table 2 Parameters for the numerical integrator scheme.

\begin{tabular}{lll}
\hline Function & Parameter & Value \\
\hline \multirow{4}{*}{ ode45 } & Relative error tolerance & $10^{-5}$ \\
\cline { 2 - 3 } & Absolute error tolerance & $10^{-5}$ \\
\cline { 2 - 3 } & Maximum step size & $0.001 \mathrm{~s}$ \\
\cline { 2 - 3 } fmincon & Report time step & $0.001 \mathrm{~s}$ \\
\hline & Optimization algorithm & $\mathrm{sqp}$ \\
\cline { 2 - 3 } & Step tolerance & $10^{-8}$ \\
\cline { 2 - 3 } & Function Tolerance & $10^{-10}$ \\
\hline
\end{tabular}

\subsection{Wheelset running on a tangent track}

As first example of application, a single wheelset running on a tangent track is considered, and its initial forward velocity is equal to $10 \mathrm{~m} / \mathrm{s}$. This mechanical system does not have constrains, and the external forces that act on the system are the gravitational forces in the negative $\mathrm{z}$-direction and the wheel-rail contact forces. The total simulation time is $10 \mathrm{~s}$.

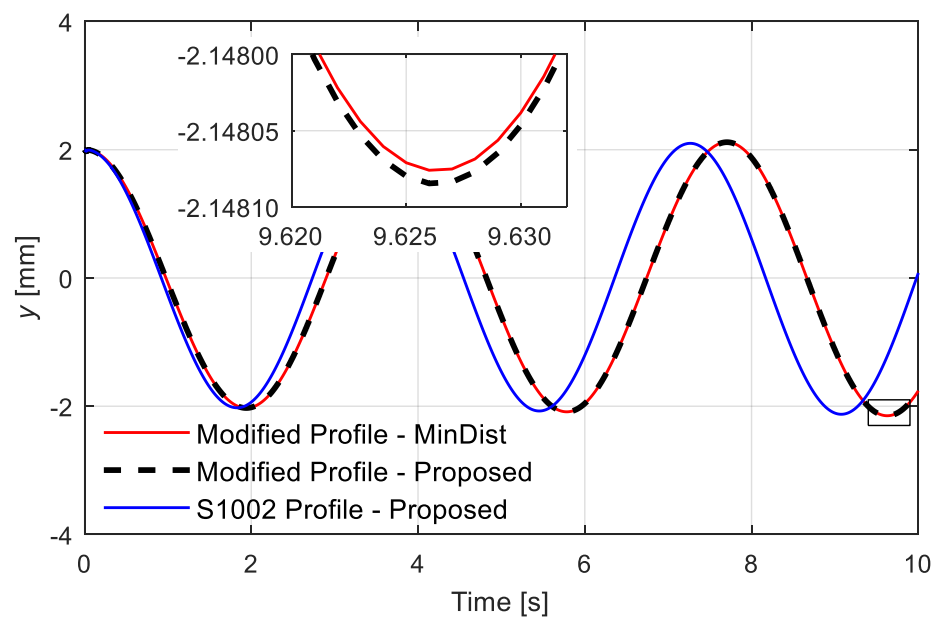

Fig. 12 Lateral position of the wheelset for the three tested scenarios of the wheelset running on a tangent track. 
Figure 12 shows the lateral position of the center of mass of the wheelset relatively to the center of the track in which three different curves are depicted. From this plot, it can be observed that the use of different methodologies for the contact detection considering the modified convex wheel profiles hardly affects the lateral response of the wheelset, since both lines are overlapped. Moreover, the augmented view shown in Fig. 12 demonstrates that the differences of using the minimum distance method or the novel proposed methodology are less than $10 \mathrm{~nm}$ almost at the end of the simulation, which is negligible. On the other hand, it is clear that the utilization of different wheel profiles has a substantial influence on the frequency of the lateral oscillation, as illustrated in Fig. 12.

Regarding the location of the contact points on the wheel surface, the results are displayed only for the simulations with the methodology proposed for the contact search since the minimum distance method shows similar outcomes. Thus, Fig. 13 illustrates the location of the contact points for both actual and modified wheel profiles. Although the lateral position of the contact points does not change significantly, it includes the modified zone of the wheel surface, which affects the results in a significant manner.

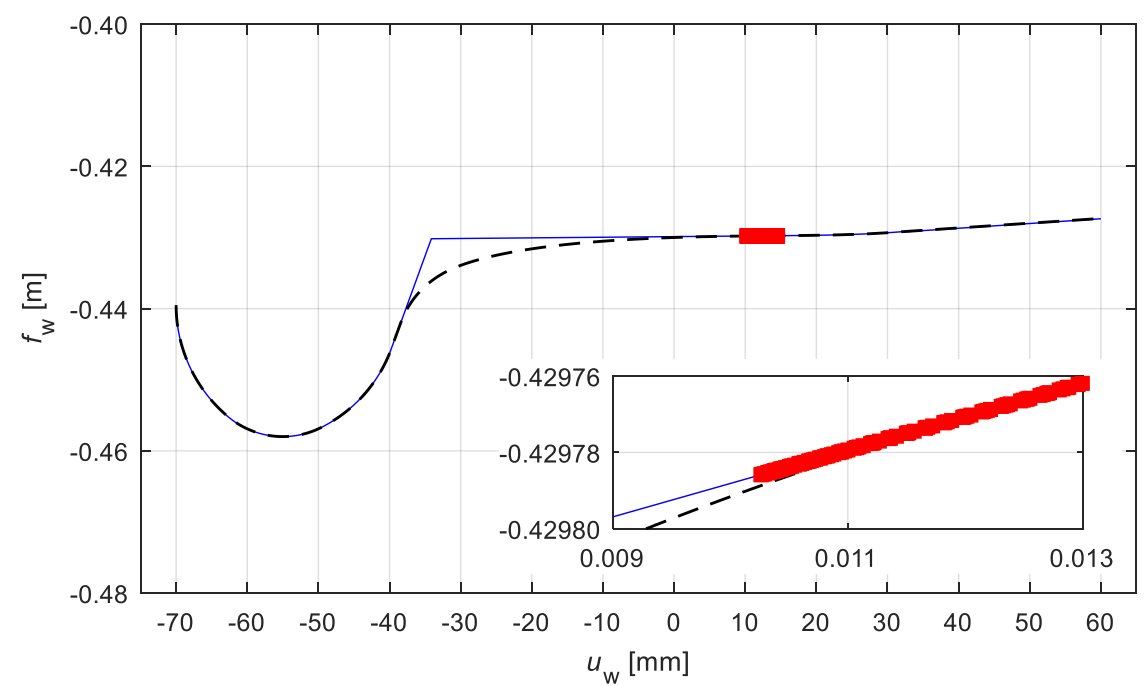

(a)

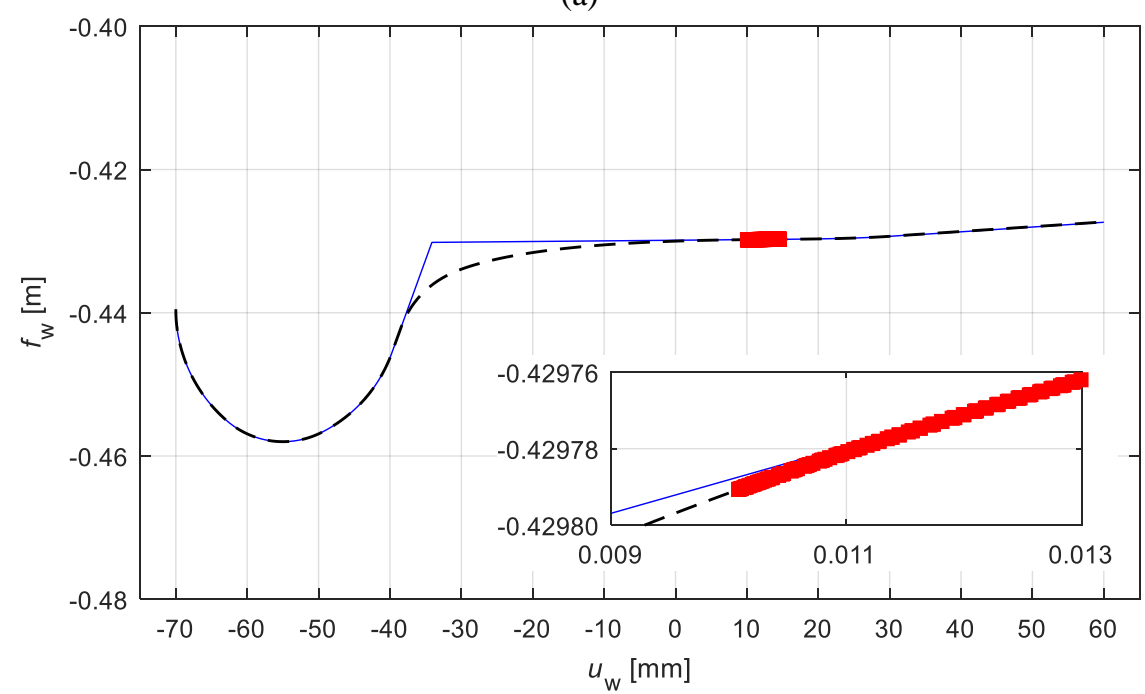

(b)

Fig. 13 Representation of both actual (- - -) and modified (-) wheel profiles, and the location of the wheel contact point ( $(\mathbf{)})$ every $0.05 \mathrm{~s}$ for (a) modified and (b) actual profiles of the wheelset running on a tangent track.

In what concerns the normal contact force, Fig. 14 shows the evolution of the magnitude of normal force on the left wheel for the three cases, which suggests that its magnitude is slightly influenced by the change in the profile. It must be noticed that since the wheelset is dropped in the track, at the beginning of the simulation the contact force exhibits high frequency due to the initial 
impact, therefore, the results are displayed only after one second of simulation, i.e., after the numerical perturbation vanishes.

In terms of computational efficiency, the ratio of CPU time for the three cases is presented in Table 3. As it can be expected, the minimum distance method is the most efficient approach, since takes advantage of being only applied to pairs of convex surfaces. In turn, for the same wheel profile, the computational cost is 3.18 times higher for the proposed methodology. Moreover, the utilization of a real wheel profile with concave zone slightly increases the computational effort of simulation with respect to that of using a simplified profile. It must be noted that the simulation time is affected by the algorithms and respective tolerances used when solving the nonlinear equations and optimization problems, which can be a source of improvement. Also, to reduce

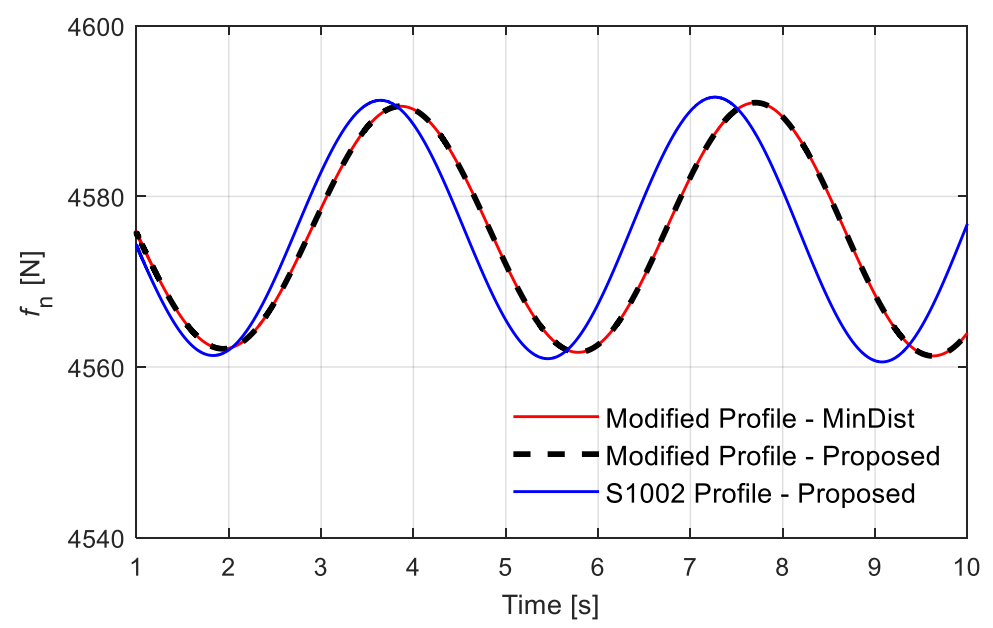

Fig. 14 Normal force magnitude in the left wheel for the three tested scenarios of the wheelset running on a tangent track.

\subsection{Bogie running on a tangent track}

The second example of application deals with a single bogie running on a tangent track similarly to the previous case. In this example, the system includes five bodies, namely, two wheelsets, two axleboxes and one bogie frame. The wheelsets and the axleboxes are constrained through revolute joints, and the axleboxes are interconnected to the bogie frame through the primary suspension. In this case, the initial forward velocity is $18.3 \mathrm{~m} / \mathrm{s}$ and the simulation time is $10 \mathrm{~s}$.

The three different scenarios are considered, being the lateral coordinate position of the leading wheelset displayed in Fig. 15. These results show that the proposed methodology can replace the minimum distance method for fully convex profiles. In addition, it can be observed that the magnitude of the lateral oscillation of the system decreases faster, when compared with the single wheelset case (Fig. 12). This fact is related to the increase of the critical velocity due to the existence of the primary suspension.

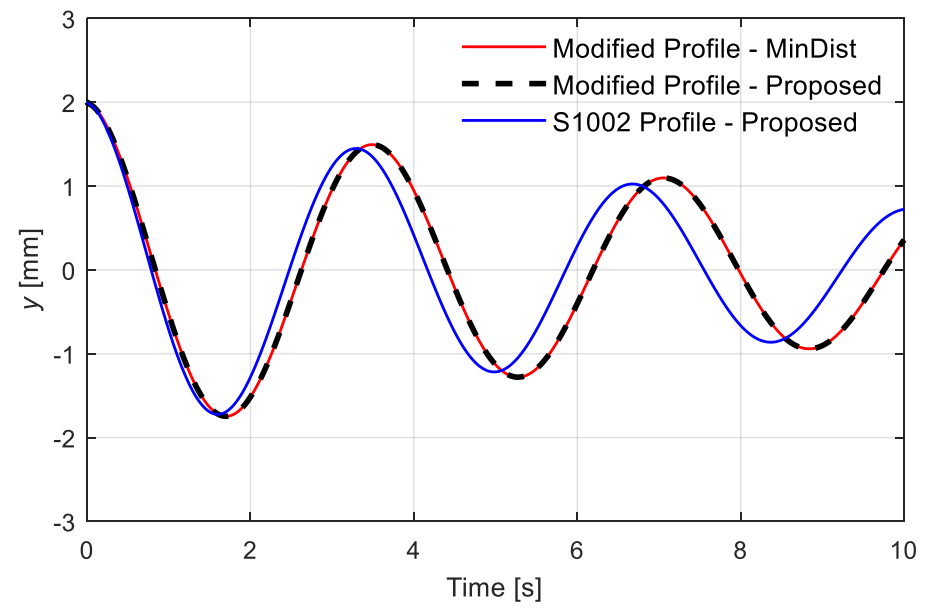

Fig. 15 Lateral position of the leading wheelset for the three tested scenarios of the bogie running on a tangent track. 
As observed in the wheelset running on a tangent track, here, the wheelsets of the bogie system also present one contact patch in each wheel. The normal contact force on the left wheel of the leading wheelset is plotted in Fig. 16. The utilization of the modified wheel profile affects the frequency of the normal force oscillation, although its magnitude remains similar. It must also be noted that the amplitude of oscillation of normal force is lower than in the single wheelset case, due to damping introduced by the primary suspension.

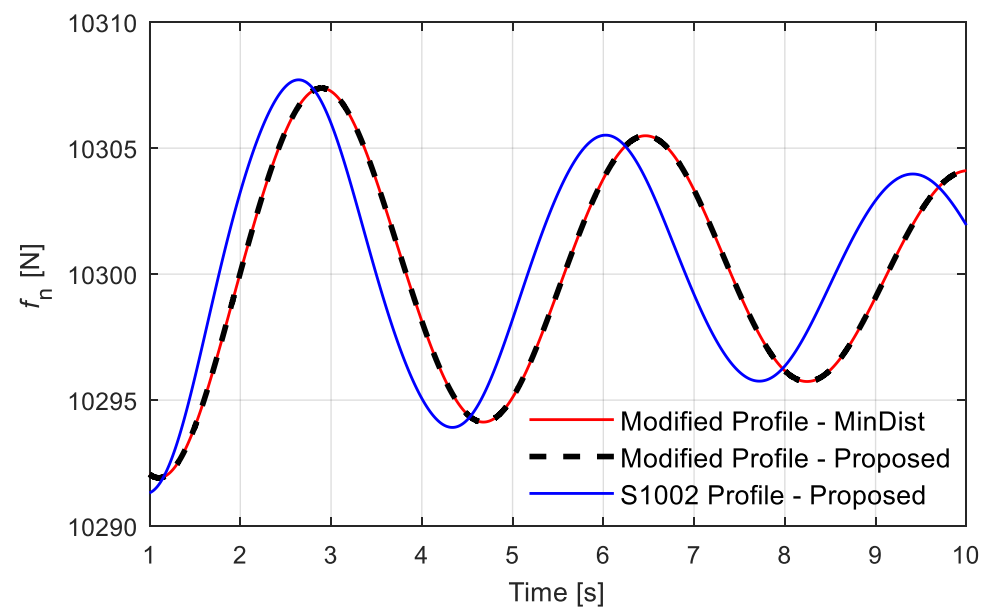

Fig. 16 Normal force magnitude in the left wheel of the leading wheelset for the three tested scenarios of the bogie running on a tangent track.

Relatively to the location of the contact points, both the lateral rail coordinate and lateral wheel coordinate are plotted for the simulations with modified and actual profiles in Fig. 17. Henceforth, the simulations with the minimum distance method are disregarded since, as previously demonstrated, the usage of different contact detection methods does not affect the results. From the analysis of Fig. 17(a), it can be observed that the location of the contact point in the rail profile is almost fixed when the modified profile is considered. Regarding the location of the contact point in the wheel profile, it is not much affect by the profiles' change, as displayed in Fig. 17(b). This corroborates the results obtained for the wheelset case in Fig. 13.

\subsection{Vehicle running on a curved track}

The final example of application of the proposed methodology consists of a trailer vehicle negotiating a left curve with a radius of $300 \mathrm{~m}$. This multibody system model includes 11 bodies, that is, five in each of the two bogies, and the carbody. The secondary suspension system is modeled to connect each bogie frame and the carbody. The vehicle starts with an initial forward velocity of $18.3 \mathrm{~m} / \mathrm{s}$, as in the previous example, being the total simulation time $41 \mathrm{~s}$.

Since in the two previous examples it was observed that the minimum distance method and the proposed methodology provide similar results, in this case, only the novel approach is considered for both types of profile. Due to the curve negotiation, the dynamic simulations present flange contact, therefore, multiple contact points occur several times for both cases.

For this application example, the contact in the right wheel of the leading wheelset of the front bogie is analyzed in detail, because it is the external wheel relatively to the curve where the flange contact occurs. Thus, Figs. 18(a) and 19(a) display the location of the several contact points in the wheel profile over time for both modified and actual profiles, respectively. The remaining subplots represent the location and shape of the contact patches for some specific moments.

Relatively to the simulation with a wheel modified profile, since the wheel tread and wheel flange are considered as two independent convex surfaces, it can be observed that at most one contact can occur in each of these segments. The flange contact occurs uninterruptedly during the curve negotiation, initiating at $5.2 \mathrm{~s}$ and ends at $37.1 \mathrm{~s}$, as demonstrated in Fig. 18(a). Although a constant location on the wheel profile is observed, its normal force magnitude has a slight variation on the initial and final stages of the contact, which can be seen by the different size of the contact ellipse in the beginning, Fig. 18(c), middle, Fig. 18(d), and end, Fig. 18(e), of flange contact. It must be noted 
that, before and after the curve negotiation, there is only contact in the wheel tread and, therefore, the vehicle exhibits a hunting motion not constrained by the flange.

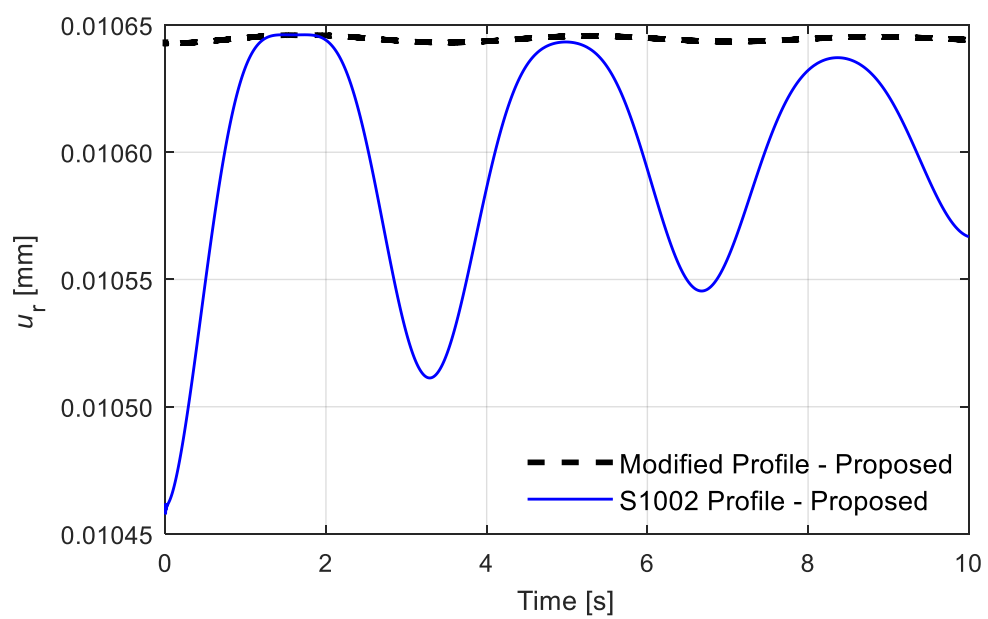

(a)

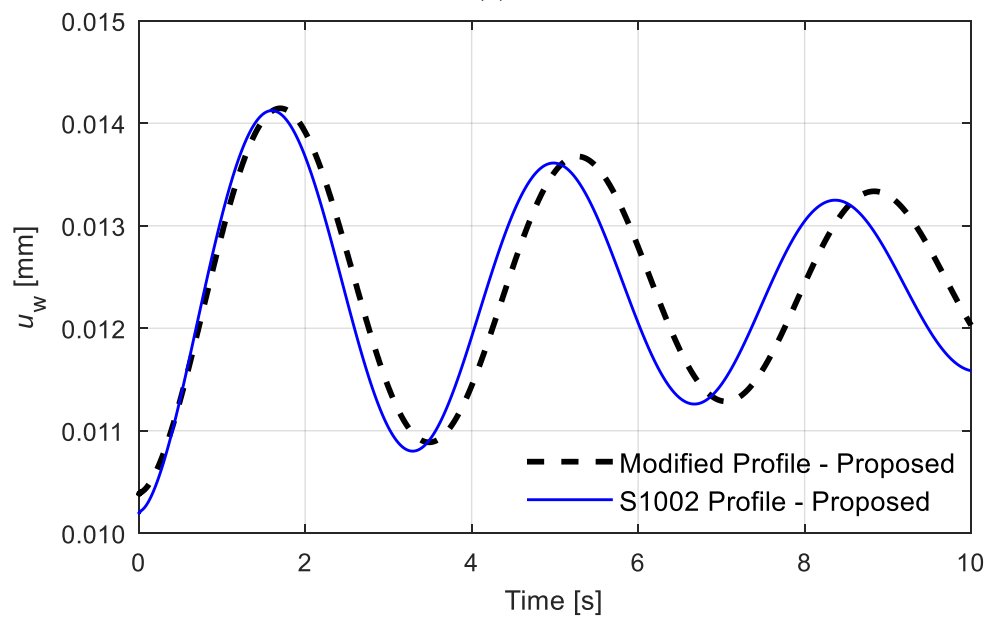

(b)

Fig. 17 Location of the contact point in the left wheel of the leading wheelset using modified and real profiles for the bogie running on a tangent track: (a) lateral rail coordinate and (b) lateral wheel coordinate.

In what concerns to the simulation of the trailer vehicle negotiating a curve with a realistic wheel profiles, it is shown that the contact is not treated independently in the wheel tread and wheel flange. One of the major differences, when compared to the previous case, is that, during most of the curve negotiation, only one contact patch exists, which is in the transition zone as represented in Fig. 19(a) and Fig. 19(d). For this case, the curve negotiation starts approximately at the same instant, i.e., $5.2 \mathrm{~s}$, and it ends slightly sooner at $36.5 \mathrm{~s}$. Moreover, the proposed methodology demonstrates the capability to detect multiple contacts at the same type for one wheel-rail pair. This is verified either in the initial or final phase of the flange contact, as shown in Fig. 19(c) and Fig.19(e), respectively. It must be highlighted that, in the latter case, even three different contact patches are detected at the same time. Overall, the contact detection in the wheel transition zone corroborates the importance of considering the actual wheel profiles. This significantly affects both the shape of the contact patch and vehicle dynamics.

Table 3 Computational time ratio for the three tested scenarios

\begin{tabular}{cccc}
\hline Simulation & $\begin{array}{c}\text { Modified Wheel Profile } \\
\text { Minimum Distance Method }\end{array}$ & $\begin{array}{c}\text { Modified Wheel Profile } \\
\text { Proposed Method }\end{array}$ & $\begin{array}{c}\text { S1002 Wheel Profile } \\
\text { Proposed Method }\end{array}$ \\
\hline Wheelset & 1.00 & 2.39 & 2.41 \\
\hline Bogie & 1.00 & 2.37 & 2.40 \\
\hline Vehicle & 1.00 & 2.11 & 2.21 \\
\hline
\end{tabular}



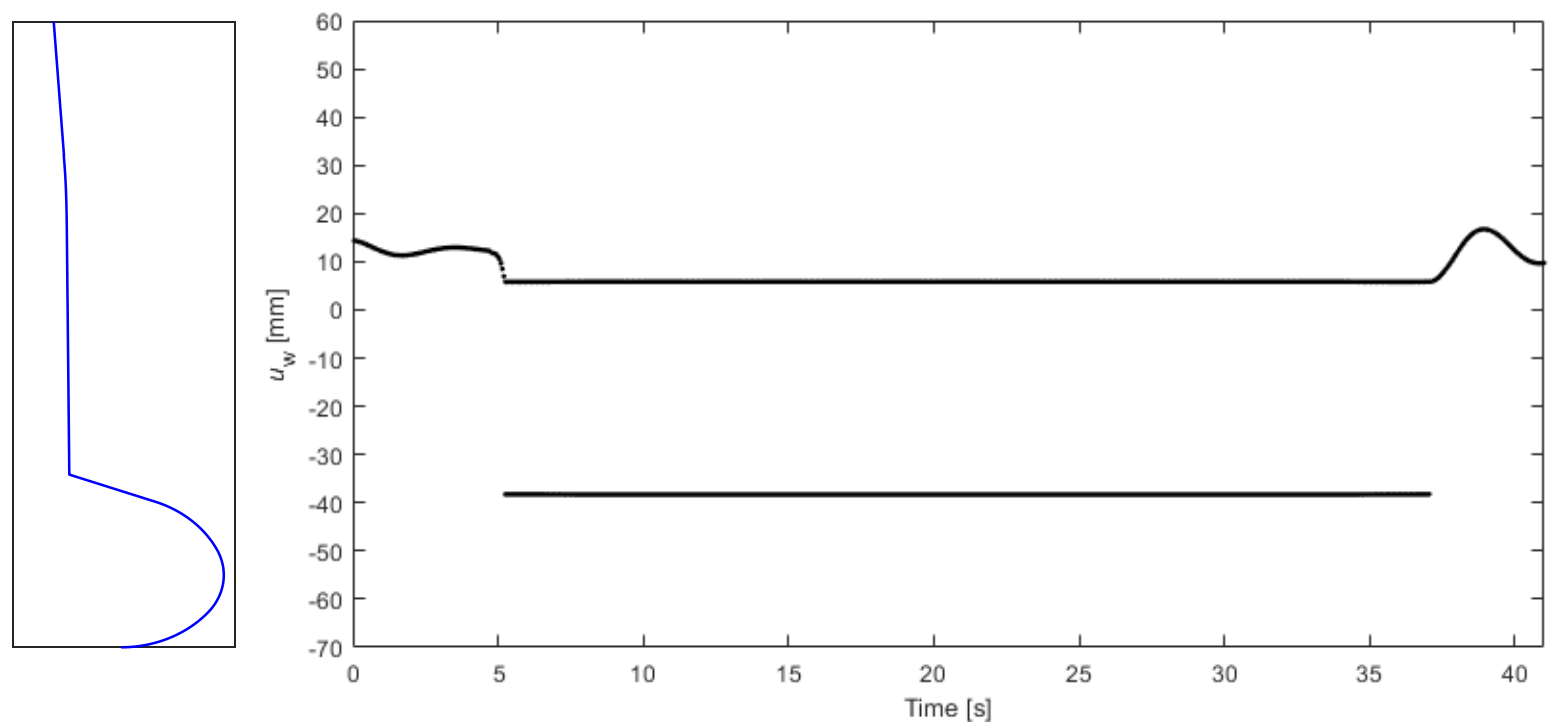

(a)

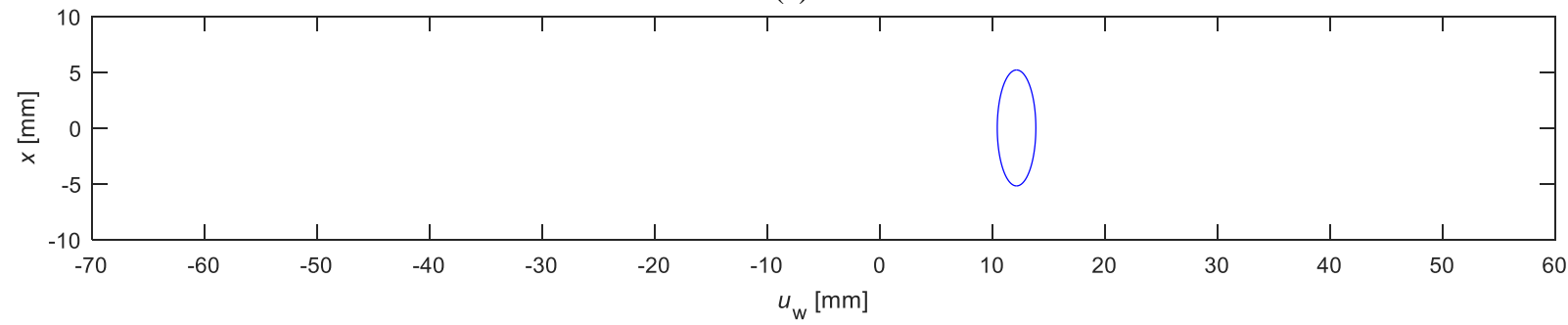

(b)

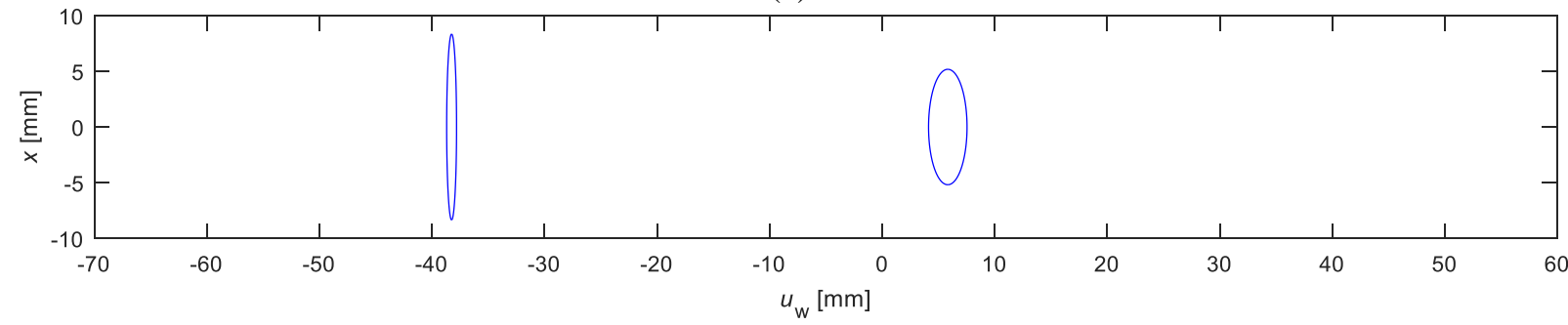

(c)

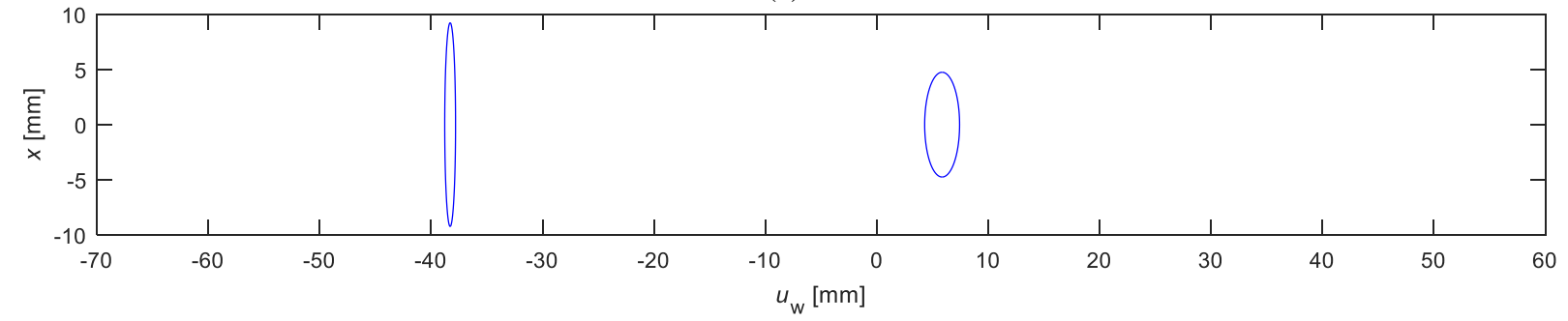

(d)

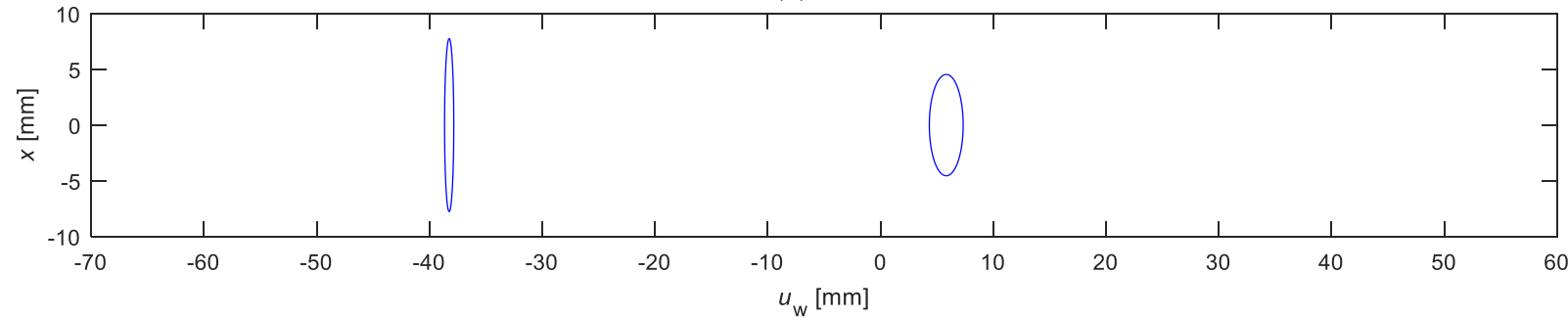

(e)

Fig. 18 Representation of (a) the location of the main point of contact for each patch over time and shape of the contact patches for (b) $t=1 \mathrm{~s} \mathrm{(c)} t=6 \mathrm{~s} \mathrm{(d)} t=20 \mathrm{~s}$ and (e) $t=36.4 \mathrm{~s}$ for the right wheel of the leading wheelset of the front bogie considering the modified wheel profile. 

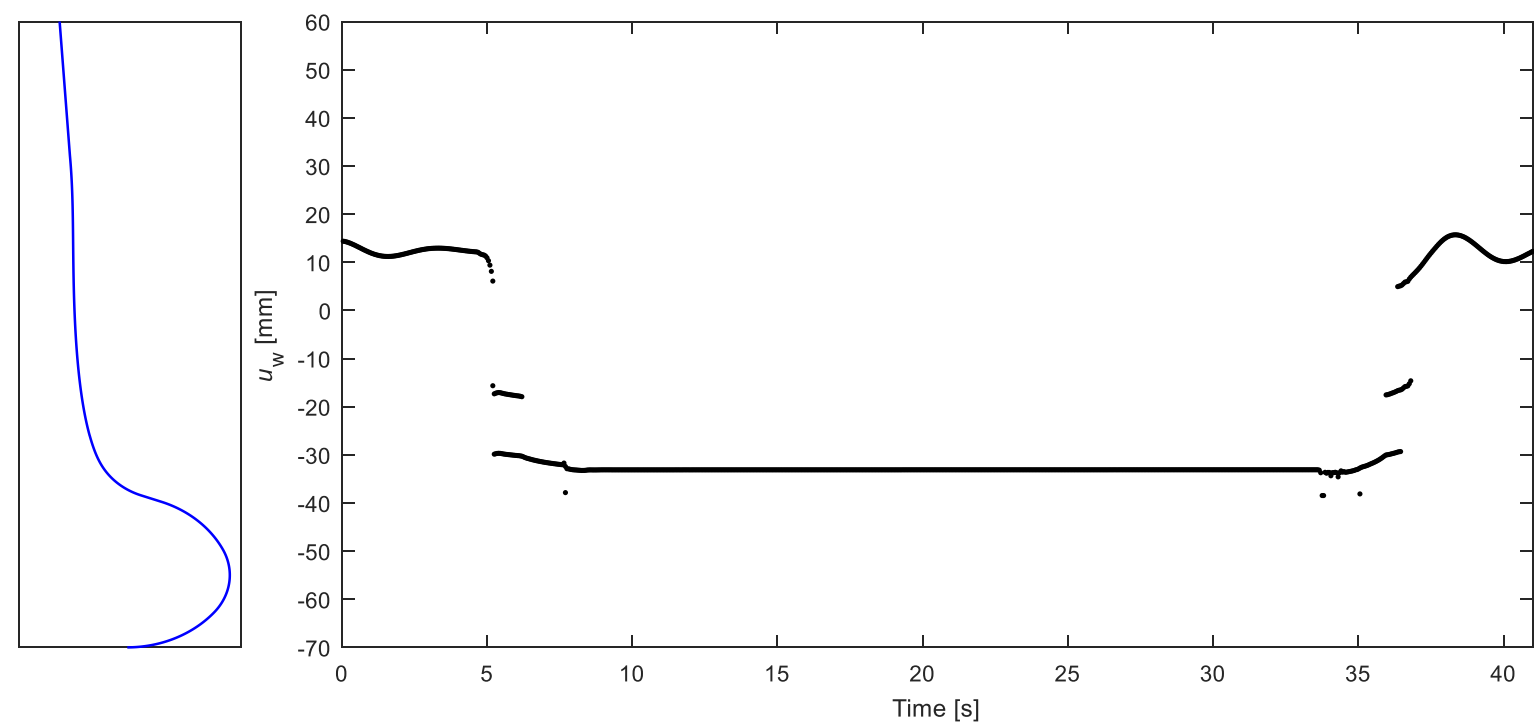

(a)

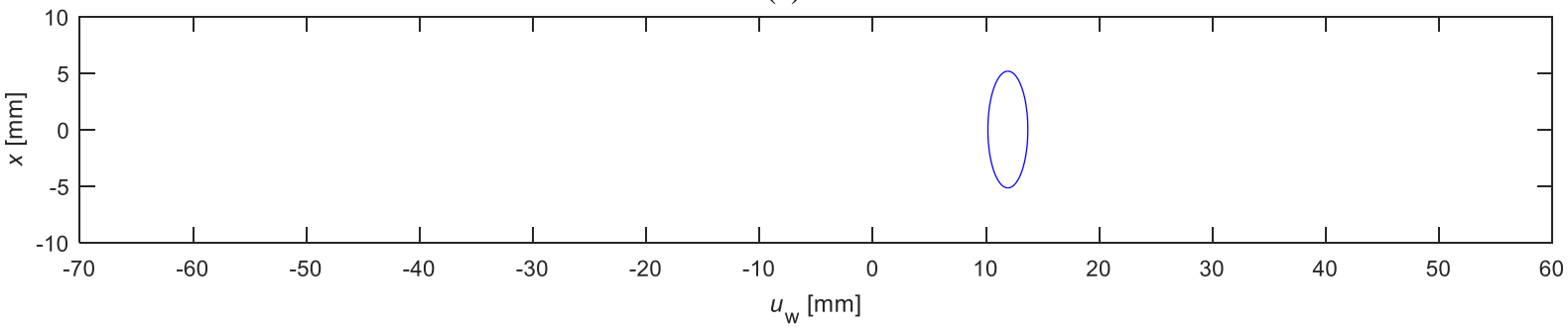

(b)

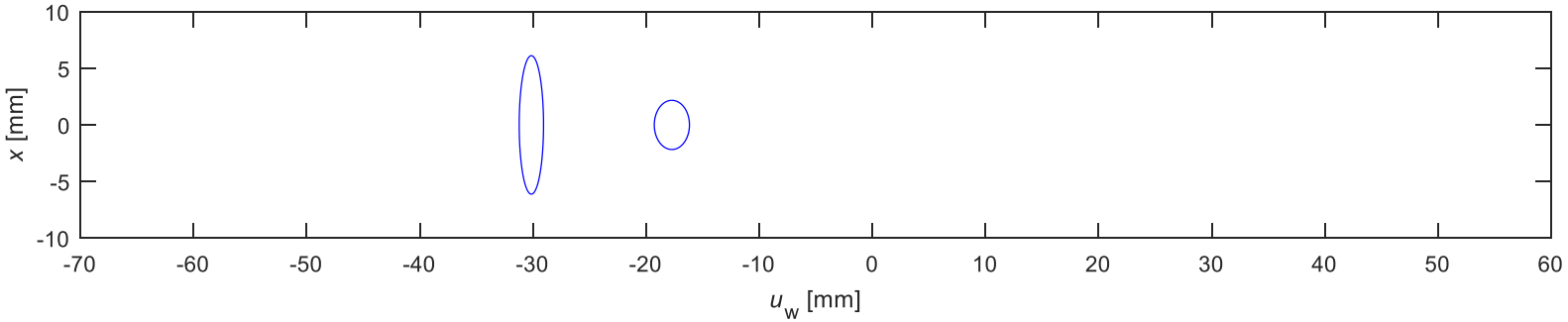

(c)

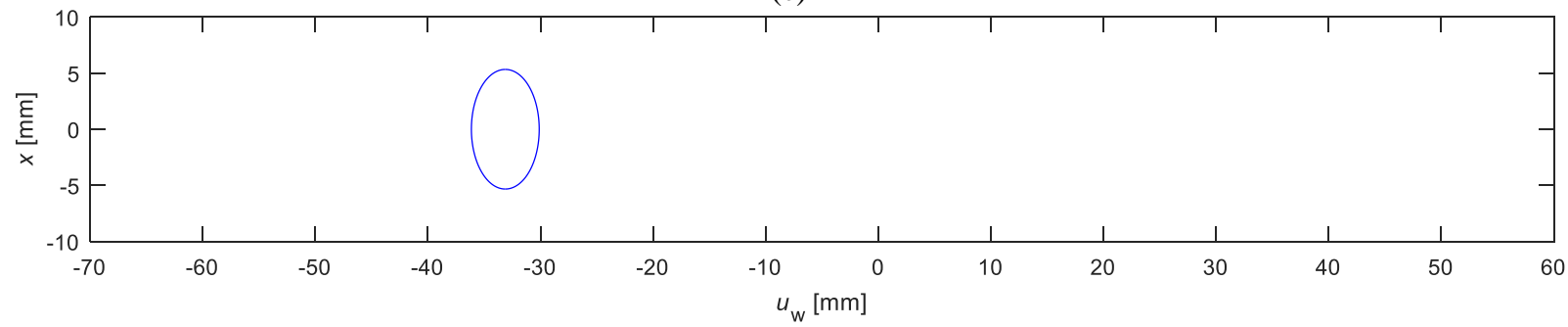

(d)

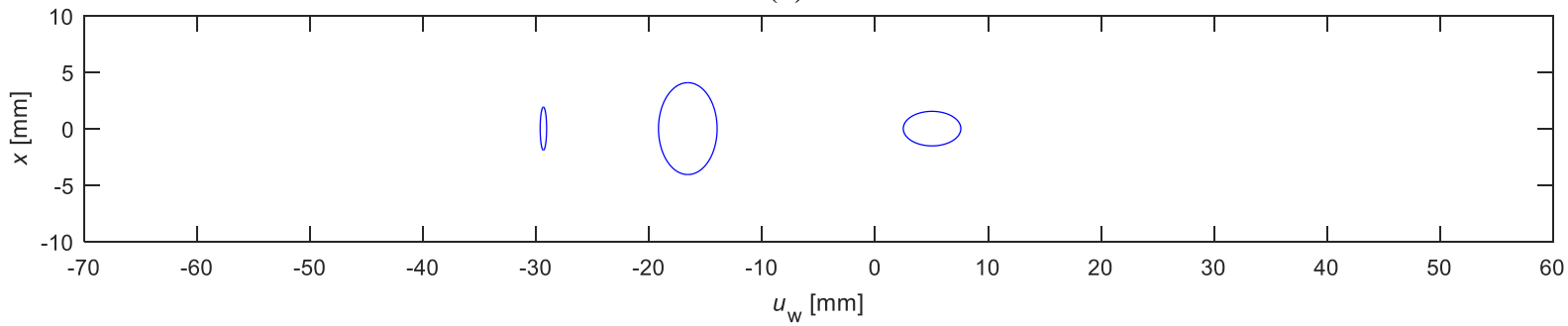

(e)

Fig. 19 Representation of (a) the location of the main point of contact for each patch over time and shape of the contact patches for (b) $t=1 \mathrm{~s} \mathrm{(c)} t=6 \mathrm{~s}$ (d) $t=20 \mathrm{~s}$ and (e) $t=36.4 \mathrm{~s}$ for the right wheel of the leading wheelset of the front bogie considering the $\mathrm{S} 1002$ wheel profile. 
In terms of computational efficiency, the ratio of CPU time for the three simulation scenarios is presented in Table 3. As expected, the minimum distance method is the most efficient approach, since it takes advantage of being only applied to pairs of convex surfaces. In turn, for the same wheel profile, the computational cost is more than two times higher for the proposed methodology. Moreover, the utilization of a real wheel profile with concave zone slightly increases the computational effort of simulation with respect to that of using a simplified profile. It must be noted that, in the simulation of the full vehicle, the CPU time ratio for the proposed methodology is lower since the importance of contact detection in the whole simulation is also lower due to vehicle modeling. The simulation time is affected by the algorithms and respective tolerances used when solving the nonlinear equations and optimization problems, which can be a source of improvement.

\section{Conclusions and future developments}

A novel approach for the contact detection between wheel and rail surfaces considering nonconvex/realistic geometries is proposed in this work. Both wheel and rail surfaces are frequently described by parametric surfaces, which take advantage of the fact that the wheel is a solid of revolution and the rail is an extruded solid. Bearing in mind that the contact search is more expeditious when the potentially colliding surfaces are convex, the wheel profiles geometric representation is commonly simplified to avoid the transition zone between the wheel tread and wheel flange, which is concave. Hence, in a multibody dynamic simulation of railway vehicles, the efficiency of the contact detection procedure can be greatly improved, and, for instance, the minimum distance method can be employed to search for the potential contact points in a continuous manner along the profile. However, for more accurate studies, the real wheel profile must be considered, which presents some numerical problems in terms of convergence of the contact points, as demonstrated in Section 3. These results show that, in a non-conformal zone, the main point of contact is well-defined with the contact conditions provided by the minimum distance method, while, in a conformal zone, the algorithm does not converge. Thus, an alternative approach to search for the contact points, which is based on the evaluation of the contact between each wheel strip and the rail, is provided here. This method allows the existence of multiple contact patches in each wheelrail pair, and searches the strip which corresponds to the maximum virtual penetration for each patch. To improve the efficiency of the proposed methodology, the assumption that the rail is locally straight is used, which expedites the calculation of some of the surface's parameters. Although this novel approach proves to be more than two times slower than the minimum distance method, it exploits the fact that the wheel is a solid of revolution to be divided into strips, which allows the search of contact points in its concave zone. Thus, the dynamic simulation of railway vehicles can be performed considering the actual wheel profile, without geometric simplifications. The effectiveness of the proposed methodology is verified in three different application examples, namely a single wheelset running on a tangent track, a single bogie running on a tangent track and a trailer vehicle running on a curved track. These simulations demonstrated that the minimum distance method and the proposed approach provide the same results when considering the simplified wheel profile, both in terms of bodies motion and contact forces. In turn, although the magnitude of the contact forces is similar for the cases where the actual wheel profile and the simplified one are considered, the dynamic response of the system is significantly influenced, namely a higher frequency in the hunting motion is observed. The location of the main points of contact is also altered, mainly in the rail surface. The dynamic simulations of the trailer vehicle negotiating a curve lead to the existence of flange contact which exhibits the ability of the proposed methodology to deal with multiple contact patches for the same pair of potential contacting surfaces.

The main focus of the present work is on the contact detection procedure and on the definition of the contacting geometries, however, for improving the accuracy of the wheel-real contact modelling, further developments on the evaluation of contact forces are required. Firstly, the utilization of Hertzian contact models involves the assumption of several simplifications which might be significantly violated for some wheel-rail configurations, therefore, non-Hertzian contact 
models must be considered for both normal and tangential forces. Secondly, when the contact is detected in a conformal zone, the concept of contact point becomes invalid, since the contact zone cannot be represented by a single point. In this case, the assumption of a planar contact patch is also not well-founded, therefore, a curved contact surface needs to be taken into account. Finally, with more advanced contact models, i.e., that provide the normal pressure and surface tractions, the wear evaluation can be performed which allows to study the evolution of the wheels' profiles during train service.

\section{Acknowledgments}

The first and second authors are supported by the Portuguese Foundation for Science and Technology (FCT) under grant PD/BD/114154/2016, MIT Portugal Program, and SFRH/BD/96695/2013, respectively. This work has been supported by FCT with the reference project POCI-01-0145-FEDER028424, by FEDER funds through the COMPETE 2020 - Programa Operacional Competitividade e Internacionalização. This work is also supported by FCT with the reference project UIDB/04436/2020 and through IDMEC, under LAETA, project UIDB/50022/2020.

\section{References}

[1] Antunes, P., Magalhães, H., Ambrósio, J., Pombo, J., Costa, J.: A co-simulation approach to the wheel-rail contact with flexible railway track. Multibody System Dynamics, 45 (2), 245-272 (2019)

[2] Apezetxea, I.S., Perez, X., Casanueva, C., Alonso, A.: Modelling stochastic excitations for a fast wear calculation methodology. Vehicle System Dynamics (2019) https://doi.org/10.1080/00423114.2019.1634275

[3] Magalhães H., Marques, F., Liu, B., Antunes, P., Pombo, J., Flores, P., Ambrósio, J., Piotrowski, J., Bruni, S.: Implementation of a non-Hertzian contact model for railway dynamic application. Multibody System Dynamics, 48 (1), 41-78 (2020)

[4] Teng, W., Shi, H., Luo, R., Zeng, J., Huang, C.: Improved nonlinear model of a yaw damper for simulating the dynamics of a high-speed train. Proceedings of the Institution of Mechanical Engineers, Part F: Journal of Rail and Rapid Transit, 233 (7), 651-665 (2019)

[5] Polach, O., Evans, J.: Simulations of Running Dynamics for Vehicle Acceptance: Application and Validation. International Journal of Railway Technology, 2 (4), 59-84 (2013)

[6] Polach, O., Böttcher, A., Vannucci, D., Sima, J., Schelle, H., Chollet, H., Götz, G., Garcia Prada, M., Nicklisch, D., Mazzola, L., Berg, M., Osman, M.: Validation of simulation models in the context of railway vehicle acceptance. Proceedings of the Institution of Mechanical Engineers, Part F: Journal of Rail and Rapid Transit, 229 (6), 729-754 (2015)

[7] Magalhães, H., Madeira, J.F.A., Ambrósio, J., Pombo, J.: Railway vehicle performance optimisation using virtual homologation. Vehicle System Dynamics, 54 (9), 1177-1207 (2016)

[8] Magalhães, H., Pombo, J., Ambrósio, J., Madeira, J.F.A.: Rail vehicle design optimization for operation in a mountainous railway track. Innovative Infrastructure Solutions, 2 (1), no. 31 (2017)

[9] Xiao, X., Jin, X., Deng, Y., Zhou, Z.: Effect of curved track support failure on vehicle derailment. Vehicle System Dynamics, 46 (11), 1029-1059 (2008)

[10] Sunami, H., Termichi, Y., Adachi, M.: An Analytical Study of Derailed Vehicle Motion from Wheel-Sleeper Impacts. International Journal of Railway Technology, 2 (2), 35-63 (2013)

[11] Pascal, J.P.: Reliability of High Speed Dynamical Derailment Simulations. International Journal of Railway Technology, 3 (3), 41-54 (2014)

[12] Matsumoto, A., Michitsuji, Y., Tobita, Y.: Analysis of Train-Overturn Derailments caused by Excessive Curving Speed. International Journal of Railway Technology, 5 (2), 27-45 (2016)

[13] Bruni, S., Vinolas, J., Berg, M., Polach, O., Stichel, S.: Modelling of suspension components in a rail vehicle dynamics context. Vehicle System Dynamics 49 (7), 1021-1072 (2011) 
[14] Pugi, L., Conti, R., Nocciolini, D., Galardi, E., Meli, E.: A Comprehensive Tool for the Optimization of Traction and Braking systems with respect to the Application of Energy Storage devices. International Journal of Railway Technology, 4 (1), 69-93 (2015)

[15] Wang, Z., Mei, G., Xiong, Q., Yin, Z., Zhang, W.: Motor car-track spatial coupled dynamics model of a high-speed train with traction transmission systems. Mechanism and Machine Theory, 137, 386-403 (2019)

[16] Pombo, J.C., Ambrósio, J.A.C.: Application of a wheel-rail contact model to railway dynamics in small radius curved tracks. Multibody System Dynamics, 19 (1-2), 91-114 (2008)

[17] Braghin, F., Lewis, R., Dwyer-Joyce, R.S., Bruni, S.: A mathematical model to predict railway wheel profile evolution due to wear. Wear, 261(11-12), 1253-1264 (2006)

[18] Pombo, J., Ambrósio, J., Pereira, M., Lewis, R., Dwyer-Joyce, R., Ariaudo, C., Kuka, N.: Development of a wear prediction tool for steel railway wheels using three alternative wear functions. Wear, 271 (1-2), 238-245 (2011)

[19] Pombo, J., Ambrósio, J., Pereira, M., Verardi, R., Ariaudo, C., Kuka, N.: Influence of Track Conditions and Wheel Wear State on the Loads Imposed on the Infrastructure by Railway Vehicles. Computers and Structures, 89 (21-22), 1882-1894 (2011)

[20] Pombo, J.: Application of a Computational Tool to Study the Influence of Worn Wheels on Railway Vehicle Dynamics. Journal of Software Engineering and Applications, 5, 51-61 (2012)

[21] Sugiyama, H., Yada, M., Yamamoto, H., Kurihara, J., Ohbayashi, H., Shimokawa, Y., Mizuno, M., Tanimoto, M.: Wheel and Rail Profile Wear on Small Radius Curved Tracks and its Effect on Derailment Coefficients: Measurement and Simulation. International Journal of Railway Technology, 2 (4), 85-98 (2013)

[22] Ekberg, A., Åkesson, B., Kabo, E.: Wheel/rail rolling contact fatigue - Probe, predict, prevent. Wear, 314 (1-2), 2-12 (2014)

[23] Hossein-Nia, S., Sichani, M.S., Stichel, S., Casanueva, C.: Wheel life prediction model-an alternative to the FASTSIM algorithm for RCF. Vehicle System Dynamics, 56 (7), 1051-1071 (2018)

[24] Alonso, A., Guiral, A., Gimenez, J.G.: Wheel Rail Contact: Theoretical and Experimental Analysis. International Journal of Railway Technology, 2 (4), 15-32 (2013)

[25] Meymand, S.Z., Keylin, A., Ahmadian, M.: A survey of wheel-rail contact models for rail vehicles. Vehicle System Dynamics, 54(3), 386-428 (2016)

[26] Gilardi, G., Sharf, I.: Literature survey of contact dynamics modelling. Mechanism and Machine Theory, 37 (10), 1213-1239 (2002)

[27] Shabana, A.A., Zaazaa, K.E., Escalona, J.L., Sany, J.R.: Development of elastic force model for wheel/rail contact problems. Journal of Sound and Vibration, 269 (1-2), 295-325 (2004)

[28] Pfeiffer, F., Foerg, M., Ulbrich, H.: Numerical aspects of non-smooth multibody dynamics. Computer Methods in Applied Mechanics and Engineering, 195 (50-51), 6891-6908 (2006)

[29] Schiehlen, W., Guse, N., Seifried, R.: Multibody dynamics in computational mechanics and engineering applications. Computer Methods in Applied Mechanics and Engineering, 195 (41-43), 5509-5522 (2006)

[30] Khulief, Y.A.: Modeling of impact in multibody systems: An overview. Journal of Computational and Nonlinear Dynamics, 8 (2), no. 021012 (2013)

[31] Marques, F., Isaac, F., Dourado, N., Souto, A.P., Flores, P., Lankarani, H.M.: A Study on the Dynamics of Spatial Mechanisms with Frictional Spherical Clearance Joints. Journal of Computational and Nonlinear Dynamics, 12 (5), no. 051013 (2017) 
[32] Machado, M., Moreira, P., Flores, P., Lankarani, H.M.: Compliant contact force models in multibody dynamics: Evolution of the Hertz contact theory. Mechanism and Machine Theory, 53, 99-121 (2012)

[33] Skrinjar, L., Slavič, J., Boltežar, M.: A review of continuous contact-force models in multibody dynamics. International Journal of Mechanical Sciences, 145, 171-187 (2018)

[34] Ma, X., Wang, P., Xu, J., Chen, R.: Comparison of non-Hertzian modeling approaches for wheelrail rolling contact mechanics in the switch panel of a railway turnout. Proceedings of the Institution of Mechanical Engineers, Part F: Journal of Rail and Rapid Transit, 233 (4), 466-476 (2019)

[35] Malvezzi, M., Meli, E., Falomi, S., Rindi, A.: Determination of wheel-rail contact points with semianalytic methods. Multibody System Dynamics, 20, 327-358 (2008)

[36] Fisette, P., Samin, J.C.: A new wheel/rail contact model for independent wheels. Archive of Applied Mechanics, 64, 180-191 (1994)

[37] Shabana, A.A., Tobaa, M., Sugiyama, H., Zaazaa, K.E.: On the Computer Formulations of the Wheel/Rail Contact Problem. Nonlinear Dynamics, 40 (2), 169-193 (2005)

[38] Sugiyama, H., Suda, Y.: On the Contact Search Algorithms for Wheel/Rail Contact Problems. Journal of Computational and Nonlinear Dynamics, 4 (4), 041001 (2009)

[39] Recuero, A.M., Shabana, A.A.: A Simple Procedure for the Solution of Three-Dimensional Wheel/Rail Conformal Contact Problem. Journal of Computational and Nonlinear Dynamics, 9(3), 034501 (2014)

[40] Escalona, J.L., Aceituno, J.F., Urda, P., Balling, O.: Railway multibody simulation with the knifeedge-equivalent wheel-rail constraint equations. Multibody System Dynamics, (2019) https://doi.org/10.1007/s11044-019-09708-x

[41] Pombo, J., Ambrósio, J., Silva, M.: A new wheel-rail contact model for railway dynamics. Vehicle System Dynamics, 45, 165-189 (2007)

[42] Liu, B., Bruni, S., Vollebregt, E.: A non-Hertzian method for solving wheel-rail normal contact problem taking into account the effect of yaw. Vehicle System Dynamics, 54 (9), 1226-1246 (2016)

[43] Carter, F.W.: The electric locomotive. Minutes of the Proceedings of the Institution of Civil Engineers, 201, pp. 221-252 (1916)

[44] Wickens, A.H.: The dynamic stability of railway vehicle wheelsets and bogies having profiled wheels. International Journal of Solids and Structures, 1 (3), 319-341 (1965)

[45] Elkins, J.A.: Prediction of wheel/rail interaction: the state-of-the-art. Vehicle System Dynamics, 20(sup1), 1-27 (1992)

[46] UIC 510-2. Trailing Stock: Wheels and Wheelsets. Conditions Concerning the Use of Wheels of Various Diameters. (2004)

[47] BS EN 13674-1: 2011. Railway applications - Track - Rail - Part 1: Vignole railway rails 46 kg/m and above. (2011)

[48] Persson, I., Iwnicki, S.D.: Optimization of railway wheel profiles using a genetic algorithm. Vehicle System Dynamics, 41, 517-527 (2004).

[49] De Boor, C.: A Practical Guide to Splines, Springer-Verlag, New York, New York (1978)

[50] Pombo, J., Ambrósio, J.: Dynamic analysis of a railway vehicle in real operation conditions using a new wheel-rail contact detection model. International Journal of Vehicle Systems Modelling and Testing, 1 (1-3), 79-105 (2005)

[51] Shabana, A.A., Tobaa, M., Sugiyama, H., Zaazaa, K.E.: On the Computer Formulations of the Wheel/Rail Contact Problem. Nonlinear Dynamics, 40 (2), 169-193 (2005) 
[52] Sugiyama, H., Araki, K., Suda, Y.: On-line and off-line wheel/rail contact algorithm in the analysis of multibody railroad vehicle systems. Journal of Mechanical Science and Technology, 23, 991996 (2009)

[53] Pombo, J., Ambrósio, J.: An alternative method to include track irregularities in railway vehicle dynamic analyses. Nonlinear Dynamics, 68, 161-176 (2012)

[54] Naeimi, M., Zakeri, J.A., Shadfar, M., Esmaeili, M.: 3D dynamic model of the railway wagon to obtain the wheel-rail forces under track irregularities. Proceedings of the Institution of Mechanical Engineers, Part K: Journal of Multi-Body Dynamics, 229 (4), 357-369 (2015)

[55] Marquis, B., Pascal, J.P.: Report on a railway Benchmark simulating a single wheelset with-out friction impacting a rigid track. Vehicle System Dynamics, 46 (1-2), 93-116 (2008)

[56] Marques, F., Magalhães, H., Ambrósio, J., Flores, P.: Approach for conformal contact detection for wheel-rail interaction. Mechanisms and Machine Science, 59, 71-78 (2019)

[57] Marques, F., Magalhaes, H., Liu, B., Pombo, J., Flores, P., Ambrósio, J., Bruni, S.: A new simplified approach to deal with conformal contact in railway dynamics. The 5th Joint International Conference on Multibody System Dynamics, June 24-28, 2018, Lisbon, Portugal, 1-13 (2018)

[58] Vollebregt, E., Segal, G.: Solving conformal wheel-rail rolling contact problems. Vehicle System Dynamics, 52(sup1), 455-468 (2014)

[59] Blanco-Lorenzo, J., Santamaria, J., Vadillo, E.G., Correa, N.: On the influence of conformity on wheel-rail rolling contact mechanics. Tribology International, 103, 647-667 (2016)

[60] Falomi, S., Malvezzi, M., Meli, E.: Multibody modeling of railway vehicles: Innovative algorithms for the detection of wheel-rail contact points. Wear, 271 (1-2), 453-461 (2011)

[61] Bozzone, M., Pennestrì, E., Salvini, P.: Dynamic analysis of a bogie for hunting detection through a simplified wheel-rail contact model. Multibody System Dynamics, 25 (4), 429-460 (2011)

[62] Sugiyama, H., Sekiguchi, T., Matsumura, R., Yamashita, S., Suda, Y.: Wheel/rail contact dynamics in turnout negotiations with combined nodal and non-conformal contact approach. Multibody System Dynamics, 27 (1), 55-74 (2012)

[63] Bozzone, M., Pennestrì, E., Salvini, P.: A lookup table-based method for wheel-rail contact analysis. Proceedings of the Institution of Mechanical Engineers, Part K: Journal of Multi-body Dynamics, 225 (2), 127-138 (2011)

[64] Escalona, J.L., Aceituno, J.F.: Multibody simulation of railway vehicles with contact lookup tables. International Journal of Mechanical Sciences, 155, 571-582 (2019)

[65] Marques, F., Magalhaes, H., Liu, B., Pombo, J., Flores, P., Ambrósio, J., Piotrowski, J., Bruni, S.: On the generation of an enhanced lookup table for wheel-rail contact models. Wear, 434-435, 202993 (2019)

[66] Piotrowski, J., Bruni, S., Liu, B., Di Gialleonardo, E.: A fast method for determination of creep forces in non-Hertzian contact of wheel and rail based on a book of tables. Multibody System Dynamics, 45 (2), 169-184 (2019)

[67] Ambrósio, J., Antunes, P., Pombo, J.: On the requirements of interpolating polynomials for path motion constraints. In: Kecskeméthy A., Geu Flores F. (eds) Interdisciplinary Applications of Kinematics. Mechanisms and Machine Science, 26, 179-197 (2015)

[68] Nikravesh, P.E.: Computer Aided Analysis of Mechanical Systems. Prentice Hall, Englewood Cliffs, New Jersey (1988)

[69] Machado, M., Flores, P., Ambrósio, J.: A lookup-table-based approach for spatial analysis of contact problems. Journal of Computational and Nonlinear Dynamics, 9(4), 41010 (2014)

[70] Gonçalves, A.A., Bernardino, A., Jorge, J., Lopes, D.S.: A benchmark study on accuracycontrolled distance calculation between superellipsoid and superovoid contact geometries. Mechanism and Machine Theory, 115, 77-96, (2017) 
[71] Ambrósio, J., Antunes, M., Santos, G.: Multibody modelling and dynamic analysis of tapered roller bearings. In: Ambrósio, J., et al. (eds.) EUROMECH Colloquium 578 Rolling Contact Mechanics for Multibody System Dynamics, Funchal, Madeira, Portugal, 1-29 (2017)

[72] Ambrósio, J., Pombo, J.: A unified formulation for mechanical joints with and without clearances/bushings and/or stops in the framework of multibody systems. Multibody System Dynamics, 42, 317-345 (2018)

[73] Hertz, H.: Über die Berührung fester elastischer Körper. Journal reine und an-gewandte Mathematik, 92, 156-171 (1881)

[74] Alves, J., Peixinho, N., Silva, M.T., Flores, P., Lankarani, H.: A comparative study on the viscoelastic constitutive laws for frictionless contact interfaces in multibody dynamics. Mechanism and Machine Theory, 85, 172-188 (2015)

[75] Flores, P., Lankarani, H.M.: Contact Force Models for Multibody Dynamics. Springer, Dordrecht (2016)

[76] Goldsmith, W.: Impact - The Theory and Physical Behaviour of Colliding Solids. Edward Arnold LTD, London, United Kingdom (1960)

[77] Lankarani, H.M.: Canonical Equations of Motion and Estimation of Parameters in the Analysis of Impact Problems, PhD Thesis, University of Arizona (1988)

[78] Pombo, J.: A Multibody Methodology for Railway Dynamics Applications, PhD Thesis, Instituto Superior Técnico (2004)

[79] Polach, O.: A Fast Wheel-Rail Forces Calculation Computer Code. Vehicle System Dynamics, Sup. 33, 728-739 (1999)

[80] Kalker, J.J.: Three-Dimensional Elastic Bodies in Rolling Contact. Kluwer Academic, Dordrecht (1990)

[81] Baumgarte, J.: Stabilization of constraints and integrals of motion in dynamical systems. Computer Methods in Applied Mechanics and Engineering, 1, 1-16 (1972)

[82] Marques, F., Souto, A.P., Flores, P.: On the constraints violation in forward dynamics of multibody systems. Multibody System Dynamics, 39 (4), 385-419 (2017)

[83] Flores, P., Machado, M., Seabra, E., Silva, M.T.: A parametric study on the Baumgarte stabilization method for forward dynamics of constrained multibody systems. Journal of Computational and Nonlinear Dynamics, 6 (1), 0110191-9 (2011) 